Mississippi State University

Scholars Junction

5-3-2019

\title{
A review of the feasibility of alternative energy system using an energy return on investment analysis
}

Joshua Hans Jeanson

Follow this and additional works at: https://scholarsjunction.msstate.edu/td

\section{Recommended Citation}

Jeanson, Joshua Hans, "A review of the feasibility of alternative energy system using an energy return on investment analysis" (2019). Theses and Dissertations. 5058.

https://scholarsjunction.msstate.edu/td/5058

This Graduate Thesis - Open Access is brought to you for free and open access by the Theses and Dissertations at Scholars Junction. It has been accepted for inclusion in Theses and Dissertations by an authorized administrator of Scholars Junction. For more information, please contact scholcomm@msstate.libanswers.com. 
A review of the feasibility of alternative energy system using an energy return on investment analysis

By

\title{
Joshua Hans Jeanson
}

\author{
Master's Thesis \\ Submitted to the Faculty of \\ Mississippi State University \\ in Partial Fulfillment of the Requirements \\ for the Degree of Master of Science \\ in Industrial and Systems Engineering \\ in the Bagley College of Engineering
}

Mississippi State, Mississippi

May 2019 
Copyright

Joshua Hans Jeanson

2019 
A review of the feasibility of alternative energy system using an energy return on investment analysis

By

Joshua Hans Jeanson

Approved:

\begin{tabular}{c}
\hline $\begin{array}{c}\text { Brian Smith } \\
\text { (Major Professor) }\end{array}$ \\
\hline Mark G. White \\
(Committee Member) \\
\hline Clayton Walden \\
(Committee Member) \\
\hline Stanley F. Bullington \\
(Graduate Coordinator) \\
\hline Jason M. Keith \\
Dean \\
Bagley College of Engineering
\end{tabular}


Name: Joshua Hans Jeanson

Date of Degree: May 3, 2019

Institution: Mississippi State University

Major Field: Industrial and Systems Engineering

Major Professor: Brian Smith

Title of Study: A review of the feasibility of alternative energy system using an energy return on investment analysis

Pages in Study 48

Candidate for Degree of Master of Science

To support further technology development and to promote the growth of a renewable biofuels industry that will satisfy the stated expectations of anticipated energy needs, it is essential that energy production systems provide a net energy gain over the course of their lifetime. As a means to provide accurate analysis to the value of alternative energy systems this paper provides a mechanism to evaluate energy systems in terms of energy generation ratios that is in terms of existing analysis techniques utilized in existing energy generation areas, such as the oil industry. This paper also proposes techniques that help perform this net energy analysis in terms of the specific economy considering the infrastructure investment. 


\section{TABLE OF CONTENTS}

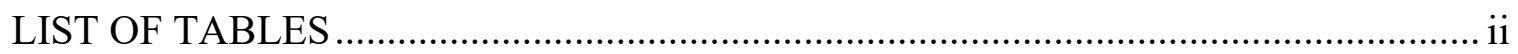

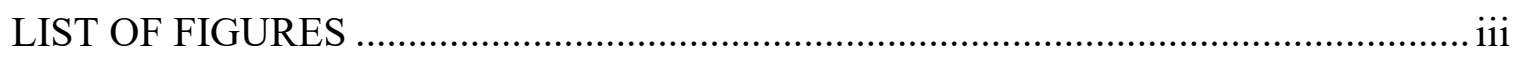

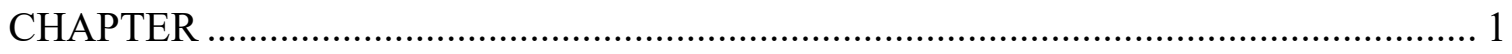

I. THE NEED FOR ALTERNATIVE ENERGY SYSTEMS ..................................1

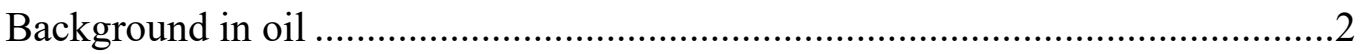

Interest in a future less dependent on oil ........................................................

II. CONSIDERATIONS IN THE OIL INDUSTRY ……………….......................

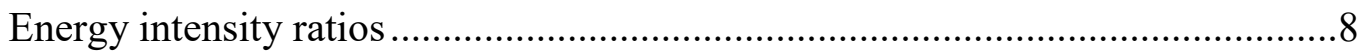

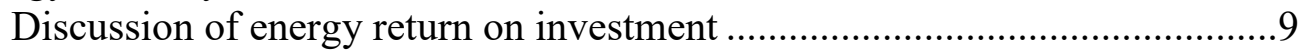

Applications of EROI ...........................................................................12

EROI for financial investments ...............................................................

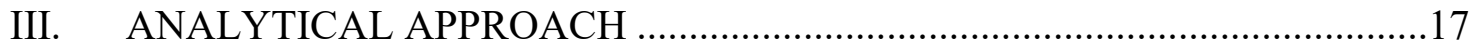

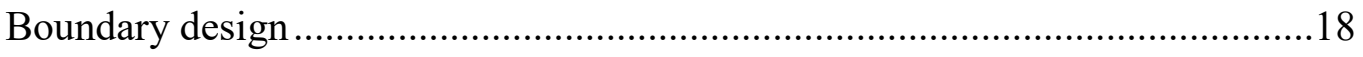

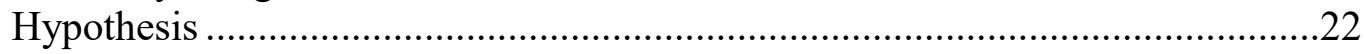

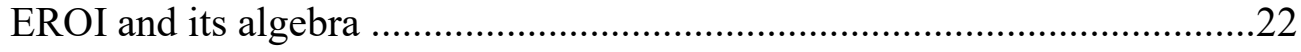

Net Present Value of Energy Flows ...........................................................2

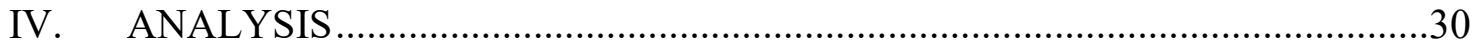

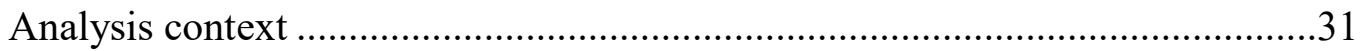

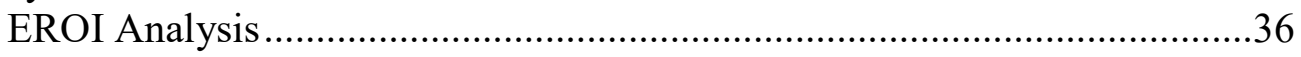

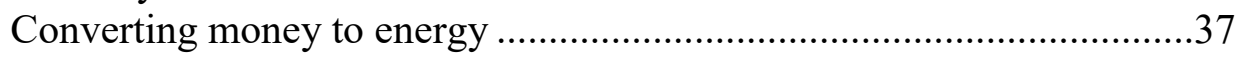

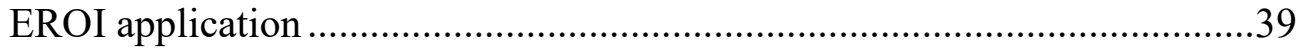

NPV analysis of energy flows .............................................................40

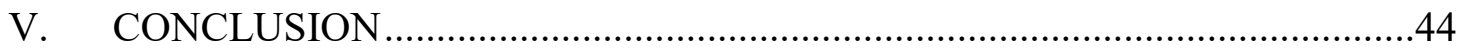

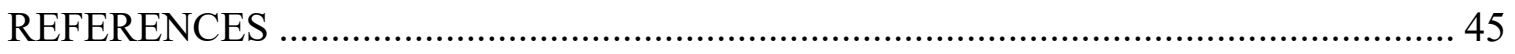




\section{LIST OF TABLES}

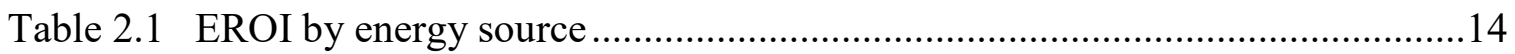




\section{LIST OF FIGURES}

Figure 1.1 Historic oil prices per barrel ................................................................

Figure 1.2 Crude oil prices correlated with major world events ..................................4

Figure 1.3 Breakdown of cost to produce a barrel of oil by country ...............................5

Figure 2.1 Costs of extraction by source …......................................................... 10

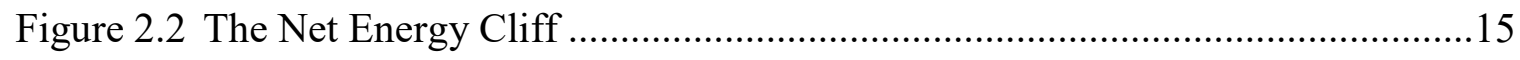

Figure 3.1 Outline of energy costs associated with non-conventional energy generation systems ........................................................... 19

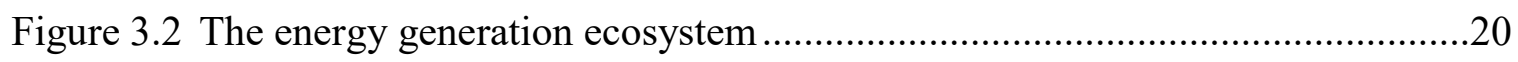

Figure 3.3 The energy generation system ............................................................21

Figure 3.4 The energy generation system's energy flows........................................24

Figure 3.5 Decision matrix based on EROI analysis result ........................................29

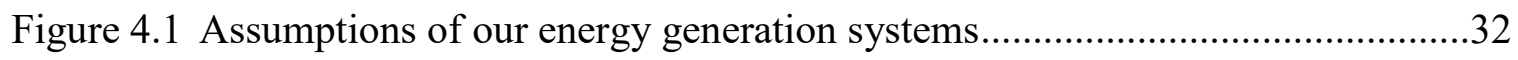

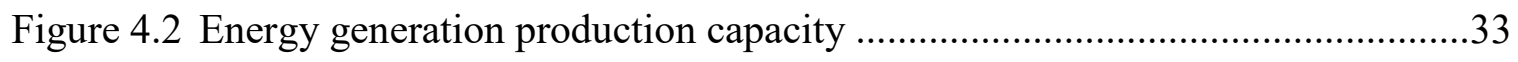

Figure 4.3 Operational costs of the energy generation systems ..................................36

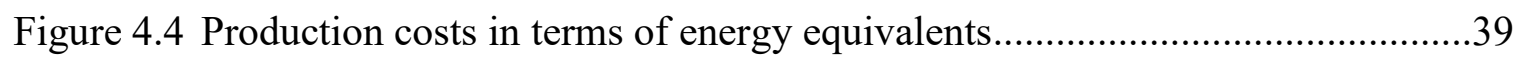

Figure 4.5 Gasification and Syngas Upgrading EROI Analysis ..................................41

Figure 4.6 Pyrolysis and Esterification EROI Analysis ..........................................42 


\section{CHAPTER I}

\section{THE NEED FOR ALTERNATIVE ENERGY SYSTEMS}

It is the intent of this paper to analyze the energy return on investment (EROI) associated with non-traditional (or alternative) sources of energy in contrast to the EROI of conventional and nonconventional energy sources. As a part of this analysis we will provide a baseline of information valuable for comparing the relative energy needed to generate energy products. This information is currently used to evaluate the cost in energy to generate energy products from conventional sources. This information will be useful for analyzing the energy costs to replace those conventional energy sources with nontraditional energy sources.

This paper will establish a framework for evaluating non-traditional energy sources as a means to set baseline expectations for the use of non-traditional energy sources in the future. ${ }^{1}$ The method of comparison proposed here intends to translate an existing energy production analysis methodology to non-traditional energy sources and to demonstrate a currency agnostic approach to project evaluation that can leverage existing engineering project analysis and investment techniques.

\footnotetext{
${ }^{1}$ This analysis can help determine the capital cost thresholds or production demands required to produce energy products from nontraditional sources at a rate above the ROI Threshold.
} 


\section{Background in oil}

A significant portion of the global industrial sector is reliant on the use of petrochemical products. From energy products consumed by nearly every human on the planet (gasoline, kerosene, diesel, etc. ...) to down-stream consumer and industrial consumables (plastics, chemicals, drugs, etc. ...), crude oil and its derivatives are essential to the modern economy. As a result the oil sector alone is a $\$ 4,000,000,000,000.00$ a year industry composed of nearly 64,000 individual corporate entities and directly employing more than 4,000,000 people. Petroleum and its related products are of critical importance to our society's energy demand and are key drivers of the modern economy (Baumeister \& Kilian, 2013).

A concern arouse during the 2000-2010 decade. As energy prices significantly increased, the impact on consumers could be felt in multiple ways: increases in costs at the gas pump, increases in costs of down-stream products (Baumeister \& Kilian, 2013), and increases in the cost of doing business across other sectors (Nigatu, Hjort, Hansen, \& Somwaru, 2014). An inherent underlying concern seemed to become widely felt as cheap oil became less abundant - could our economy survive if the cost of oil increases (OECD, 2008)? Better stated, how will our economy evolve with increasing costs of oil?

Long-term analysts began to ponder the ramifications of the end of the "cheap" crude oil production era and how it would impact the world. These analysts asked questions about developing economies, new sources of energy, and the impact of globalization. The conclusion reached by the researchers: without technological advancement and industrial alternatives a slowdown in crude oil production could dramatically impact the stability of the global economy (Supermajordammerung, 2013). As a result of this spike in energy 
costs came a second concern, are we seeing the end of the tunnel related to peak oil production?

Even more recently, the shock to global oil costs and subsequent drop in pricing has triggered tremendous speculation on the long-term pricing and consumption of oil, see Historic oil prices per barrel. This shock has led to some thoughts that open market conditions and cost of production are not the sole force driving the pricing of the energy commodity. Instead, socio-economic and geo-political factors may more immediately impact the pricing of this commodity as it is used as a tool to achieve political objects, see Crude oil prices correlated with major world events (Williams, 2011).

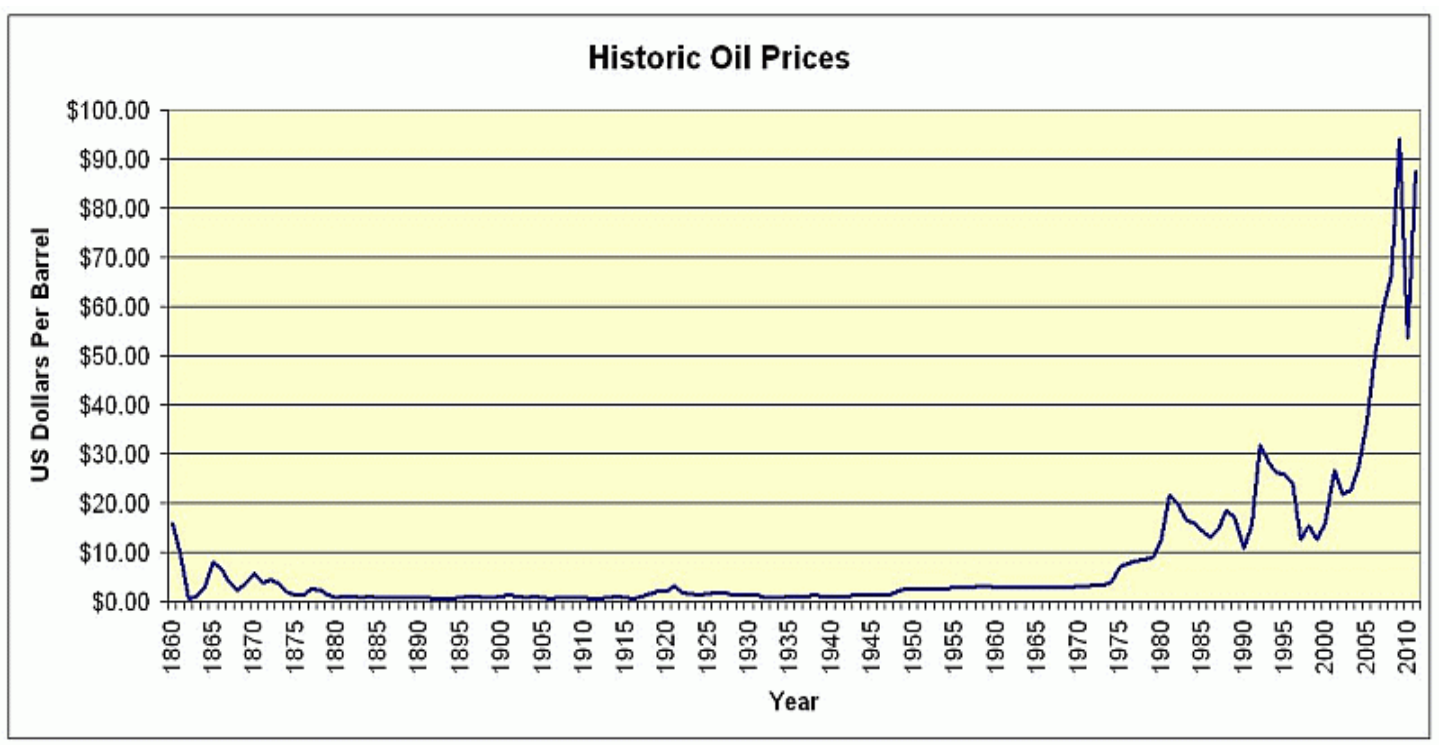

Figure 1.1 Historic oil prices per barrel 


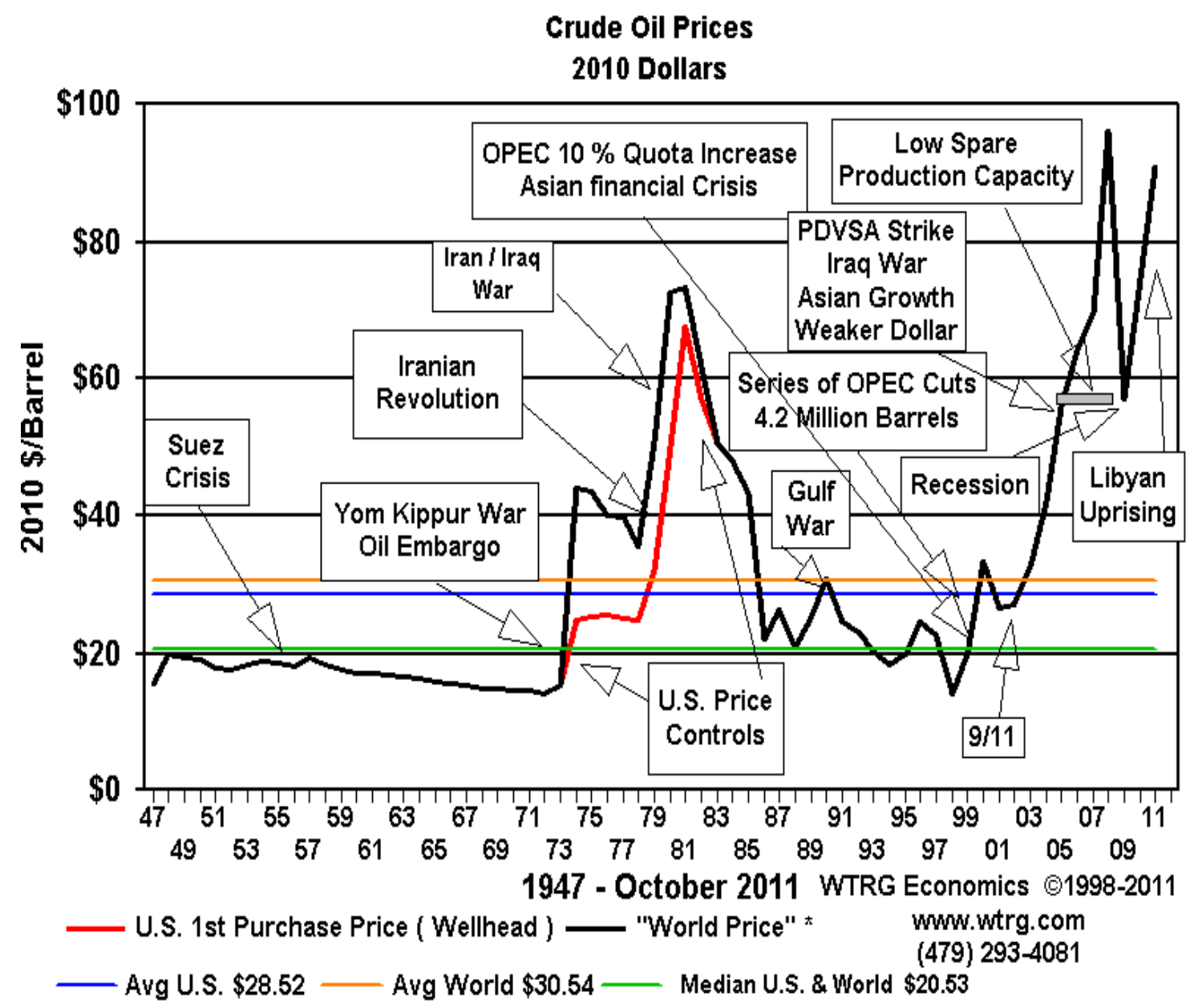

Figure 1.2 Crude oil prices correlated with major world events

Oil producers are acutely aware of the cost and viability of the crude oil source they are exploiting (Breakdown of cost to produce a barrel of oil by country) (Petroff \& Yellin, 2015). And, these producers readily make near real-time adjustments to their production capability in response to market shifts while the institutional or state owned production companies continue to produce in a manner more consistent with state demands (maintaining energy/heat availability or employment rates within the geographic region). 


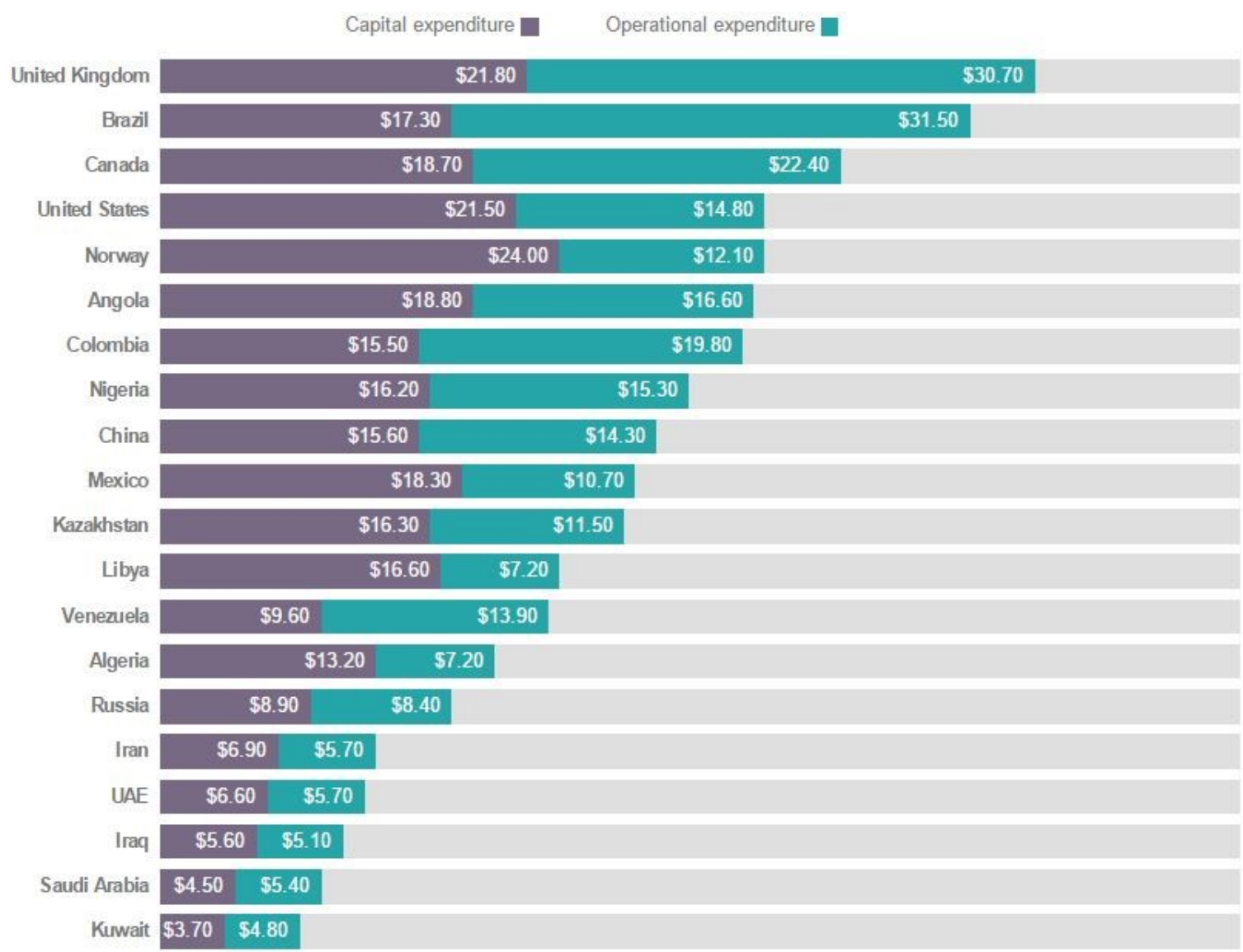

Figure 1.3 Breakdown of cost to produce a barrel of oil by country

\section{Interest in a future less dependent on oil}

In response to concerns of a post "peak oil" economy the US Government assumed the role of exploring alternative technologies to develop and promote less expensive production of unconventional and non-traditional energy sources (National Academies, 2007). The government also increased its investment in cleaner, alternative, or exploratory energy generation and storage technologies (our non-traditional energy sources). The Department of Energy began investing in high-risk, high-reward energy projects that may have otherwise gone uninvestigated through its ARPA-E program (ARPA-E, 2009). Since 
its inception the Department of Energy's ARPA-E program has invested nearly $\$ 1,250,000,000.00$ in advanced energy research within the United States. As a result of this investment there is a growing field of potential sources of alternative energy generation technologies (ARPA-E, 2016).

However these investments by the DOE tend towards proof-of-concept design and development opportunities on extreme engineering projects without a clear rationale to the viability of the energy generated from these projects (Mervis, 2017). The prevailing thought seems to indicate that we are in a basic research mode for developing better approaches to generating energy from non-traditional sources and that translational efforts will help identify and develop the most viable option(s) (Majcher, 2015).

Several research groups are taking information developed from these funded projects and analyzing how they might best fit into current industrial and economic systems. While much of this particular literature is dedicated to evaluating the feasibility of the: science, engineering economics, logistics, and supply chain concerns associated with these energy projects; very few analyze whether the energy project will achieve its primary goal of being, at best, a net positive energy investment (Marchand, 2017).

To help evaluate opportunities in the energy supply market based on nontraditional energy sources an analysis mechanism is valuable to understand whether the non-traditional source will meet some peak threshold for return on energy invested (Timmons, Harris, \& Roach, 2014). This paper seeks to repurpose and adapt an existing analysis technique utilized in the conventional oil sector for application to non-traditional energy sources. 


\section{CHAPTER II}

\section{CONSIDERATIONS IN THE OIL INDUSTRY}

Crude oil has been a chief and vital source of energy products for a significant period of modern history. Although the general consumer may identify crude as a simple, homogenized input, it actually varies widely across sources. Crude pulled from conventional sources often contains other compounds (Oxygen, Nitrogen, Sulfur, and Metals). ${ }^{2}$ These differences in mineral content provide a mechanism for distinguishing the varieties of the product. To accommodate for these differences the petrochemical industry has developed mechanisms for refining each particular variety of crude into higher value energy products and the chemicals we utilize seamlessly in the economy.

Each step in this process of producing and refining energy products requires energy.

The refining process consists of fractioning crude oil into different distillates. This process occurs through several different methodologies. Most commonly, fractional distillation is utilized. ${ }^{3}$ To increase the production of more valuable hydrocarbons from crude oil, refineries can utilize additional techniques to convert one type of hydrocarbon to another. To achieve this goal refineries can 1) break apart a larger hydrocarbon chains

\footnotetext{
${ }^{2}$ Sulfur content of crude provides just one of several ways to distinguish the quality of crude oil. For instance, crude oil with low sulfur content is known as sweet crude while crude oil with $5 \%$ of sulfur or more is known as sour crude oil.

${ }^{3}$ This occurs where the different constituents of oil are separated through their varied boiling points. The boiling ranges are linked with the amount of carbon in the fractionate. Lower carbon content products such as natural gas, naphtha and gasoline have boiling temperatures less than 100 degrees Celsius while Kerosene, gas/diesel, and lubricating oils have boiling points less than 200 degrees Celsius. Heavy oils and other residual products are heated up to 600 degrees Celsius before they boil.
} 
(cracking), ${ }^{4}$ 2) combine smaller hydrocarbon chains (unification), or 3) chemically rearrange the structure of existing hydrocarbons (alteration).

To provide some perspective on the products that can be realized from crude oil, consider that a barrel of crude oil can produce the following (US Energy Information Administration, 2017).

20 gallons of motor gasoline, 8 gallons of diesel, 4 gallons of jet fuel

5 gallons of petroleum based products (e.g. petrochemicals)

3 gallons heavy fuel/ petroleum gases, and

2 gallons of heating oil

The uniqueness of conventional oil is the relatively low cost for its production. In recovering and refining conventional oil the process is relatively straightforward. In 2009 the EIA produced information related to the costs of producing conventional oil. This information is provided in Appendix B and related in Breakdown of cost to produce a barrel of oil by country (US Energy Information Administration, 2017). As conventional energy sources are further exploited the costs associated with these energy products will continue to increase to the point where they are no longer viable.

\section{Energy intensity ratios}

Due to constant fluctuations in global currencies relative to each other certain academics and practitioners in the petroleum industry have developed a set of currency

\footnotetext{
${ }^{4}$ Cracking can be accomplished through several mechanisms. Thermal cracking occurs by using high-temperature steam to break apart larger hydrocarbon chains (such as ethane and butane) into smaller hydrocarbon chains (such as ethylene or benzene). Catalytic cracking is an alternative to thermal cracking. With catalytic cracking, large hydrocarbons chains can be broken apart through the addition of special catalysts in an appropriate environment, either heat sensitive or pressure sensitive. Once the longer chain hydrocarbons are cracked they are separated through a distillation column.
} 
independent evaluation criteria useful for determining the value of pursuing particular crude oil sources; conventional and unconventional.

\section{Discussion of energy return on investment}

Energy Return on Investment (EROI) has become a unique measure of value on investment in the energy sector (Hall, Lambert, \& Balough, 2014) (Dale, Krumdieck, \& Bodger, 2011). This measure has been explored very recently as a way to examine the value of energy obtained from investments in conventional and unconventional crude oil sources (Costs of extraction by sources) (Heun \& de Wit, 2012). A knowledge base has been developed to determine the EROI for energy products derived from conventional and alternative forms of crude and other energy generation mechanisms, such as nuclear and wind (Brandt, Englander, \& Bharadwj, 2013). However, very little practical information has been utilized to determine the EROI for nontraditional energy sources such as Fischer-Tropsch, gasification to electricity, gasification to liquid fuel, and pyrolysis. 


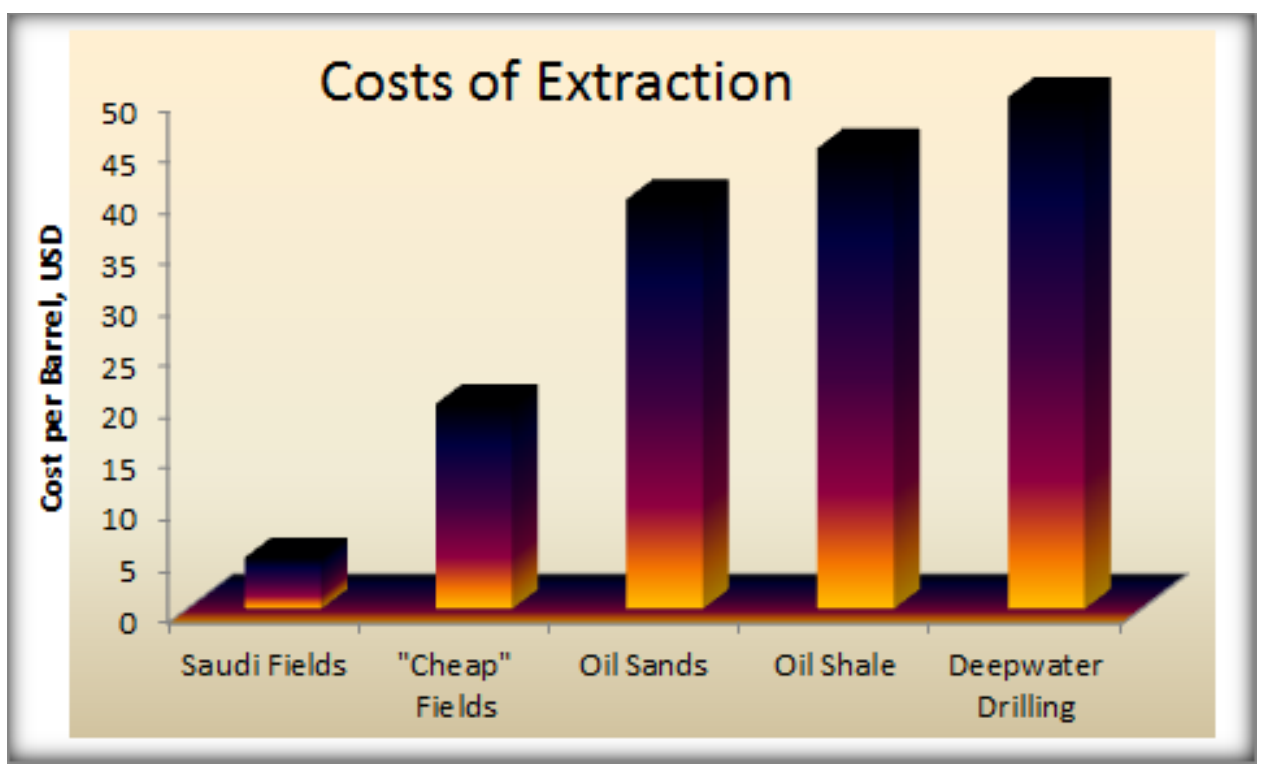

Figure 2.1 Costs of extraction by source

EROI, as first explored, is a mechanism to provide a "top down" analysis to measure the ratio of energy invested in a system to the energy obtained from the system (Murphy, 2011).

$$
E R O I=\text { Eout } / \text { Ein }
$$

The EROI analysis can also be examined through a related equation (2.1) to determine a system level approach to energy returns. This system wide approach concerns net energy flows (Murphy, 2011).

$$
\text { Net Energy }=\text { Eout }- \text { Ein }
$$

This methodology is often applied to global energy consumption and global production rates but has found use in a number of fields (organic system analysis, chemical production system analysis, etc..) (Carbajales-Dale, Barnhard, Bradnt, \& Benson, 2014). At a more local level, the energy production system can be described as total energy leaving the production system (Energy for Markets) less the energy needed to run the production 
system (System Energy) (Dale, Krumdieck, \& Bodger, 2011). This analysis is a complement to a system energy balance (2.2).

By combining these equations we can evaluate the Net Energy of an energy production system (2.3) (Murphy, 2011).

$$
\text { Net Energy }=\text { Eout } *\left[\frac{(E R O I-1)}{E R O I}\right]
$$

This methodology is utilized to determine energy generation and consumption on a macro-scale. ${ }^{5}$ The unique nature of this construct provides an agnostic approach to the current state of development; as any given system is analyzed then the energy costs associated with that system (including technological gains or logistical constraints) are evaluated to determine the EROI of the specific energy system opportunity. Thus, we can leverage this analysis to perform a unique analysis on whether an energy project is viable through a methodology that is agnostic to political, logistical, and external market factors but can accommodate unique costs associated with these concerns.

As a means for understanding the energy required by a nontraditional energy production system we can utilize a Net Energy Returns (NER) methodology to find the energy cost for converting nontraditional sources of energy into an energy product (Brandt, Englander, \& Bharadwj, 2013). We can use this framework with a defined system to analyze the net energy of the system proposed (2.4).

$$
N N E R_{m m}=\frac{\text { Energy }_{\text {out }}}{\text { Energy }_{\text {in }}+\text { Energy }_{\text {parasitic }}}
$$

\footnotetext{
${ }^{5}$ In the literature several researchers have speculated of a threshold for energy return on investment is necessary to maintain the viability of the modern economy's energy dependence. By utilizing this threshold as a minimum, we can begin a theoretical framework baseline for determining whether a proposed energy system is viable.
} 
To adjust these equations to suit our purposes, we will need to account for the unique aspects of energy costs related to non-traditional energy products. This will require us to develop a precise definition for boundaries for our energy generation system. This boundary definition will be essential in determining how to evaluate the energy (or cost in energy) of any inputs into our energy generation system - a cost determination that will be an essential portion of this paper. These costs will be particular to our feedstock of choice (be it drying costs of green biomass, sorting costs of municipal solid wastes), costs associated with sourcing material across distances, or feed costs associated with sludge treatment.

As a practical consideration, this analysis is limited to the energy value invested in a system and an analysis of the energy value directly leaving the system. As the literature has pointed out, it is often difficult to value the energy utilized in the system to create a co-product (Thomas, Choi, \& Luo, 2015). It can be even more difficult to evaluate the energy value of the co-products in many situations. To overcome this frustration we will treat the co-products as waste during an EROI analysis. It is anticipated that energy value can be determined for the co-products in terms as those utilized to determine the energy value of the inputs - something that may discussed in this paper or in future research endeavors.

\section{Applications of EROI}

EROI has become a common analytical tool for the petroleum industry. The ratio is an easy shorthand analysis for determining whether a particular reserve is viable as an exploitable production opportunity given current market conditions. For example, analysts know that an unconventional source of crude (e.g. shale or tar sands) has an EROI much 
lower than more conventional sources of oil. As a result, when oil prices drop below certain dollar thresholds on the open market we see near immediate reductions in productivity from the lower EROI related sources of energy (Smith \& Lee, 2017). This is directly attributable to the costs of production. And, as the exploration and production industry is highly attuned to the cost of production they understand, to the dollar, the value of each producing source. Inherent in this analysis is an underlying relationship between EROI and cost of production. As most unconventional sources for oil are more resource intensive to produce we can show the additional costs associated with this production. This has been contemplated in situations where non-combustible fuel sources are used to generate energy (Donohoo-Vallett, 2016). This increased use of resources for production is directly attributed to energy input, therefore EROI of these sources is lower than cheaper sources to exploit.

EROI has been measured for a number of energy product sources. Hall and Day provide actual and theoretical max EROI's for several sources of energy (EROI by energy source) (Hall, Lambert, \& Balough, 2014). 
Table 2.1 EROI by energy source

\begin{tabular}{lcc}
\hline \multicolumn{1}{c}{ Source } & Attained EROI & Theoretical Max EROI \\
\hline Domestic Oil (ca 1930) & $100: 1$ & \\
\hline Domestic Oil (ca 1970) & $20: 1$ & \\
\hline Domestic Oil (ca 2010) & $15: 1$ & \\
& & $40: 1$ \\
\hline Imported Oil (ca 1970) & $23: 1$ & $35: 1$ \\
\hline Imported Oil (ca 2005) & $17: 1$ & \\
& & $80: 1$ \\
\hline Natural Gas & $15: 1$ & $10: 1$ \\
\hline Coal (ca 2005) & $40: 1$ & $30: 1$ \\
\hline Tar Sands & $3: 1$ & $15: 1$ \\
& & \\
\hline Windmill & $8: 1$ & \\
Nuclear & $4: 1$ & \\
Firewood & $35: 1$ & \\
Bio-oil and Gasenol & $3: 1$ & \\
\hline Photovoltaic & $6: 1$ & \\
\hline
\end{tabular}

The literature related to EROI maintains a consistent concern related to these analyses specifically in regard to renewable fuel; the assumptions utilized for these predictions are inconsistent across energy feed stocks or sources (Murphy, 2011). ${ }^{6}$ These resources point to an energy cliff that indicates a minimum return on energy investment necessary to be sustainable (The Net Energy Cliff) (Hall, Lambert, \& Balough, 2014).

\footnotetext{
${ }^{6}$ In the literature several researchers have speculated of a threshold for energy return on investment is necessary to maintain the viability of the modern economy's energy dependence. By utilizing this threshold as a minimum, we can begin a theoretical framework baseline for determining whether a proposed energy system is viable.
} 


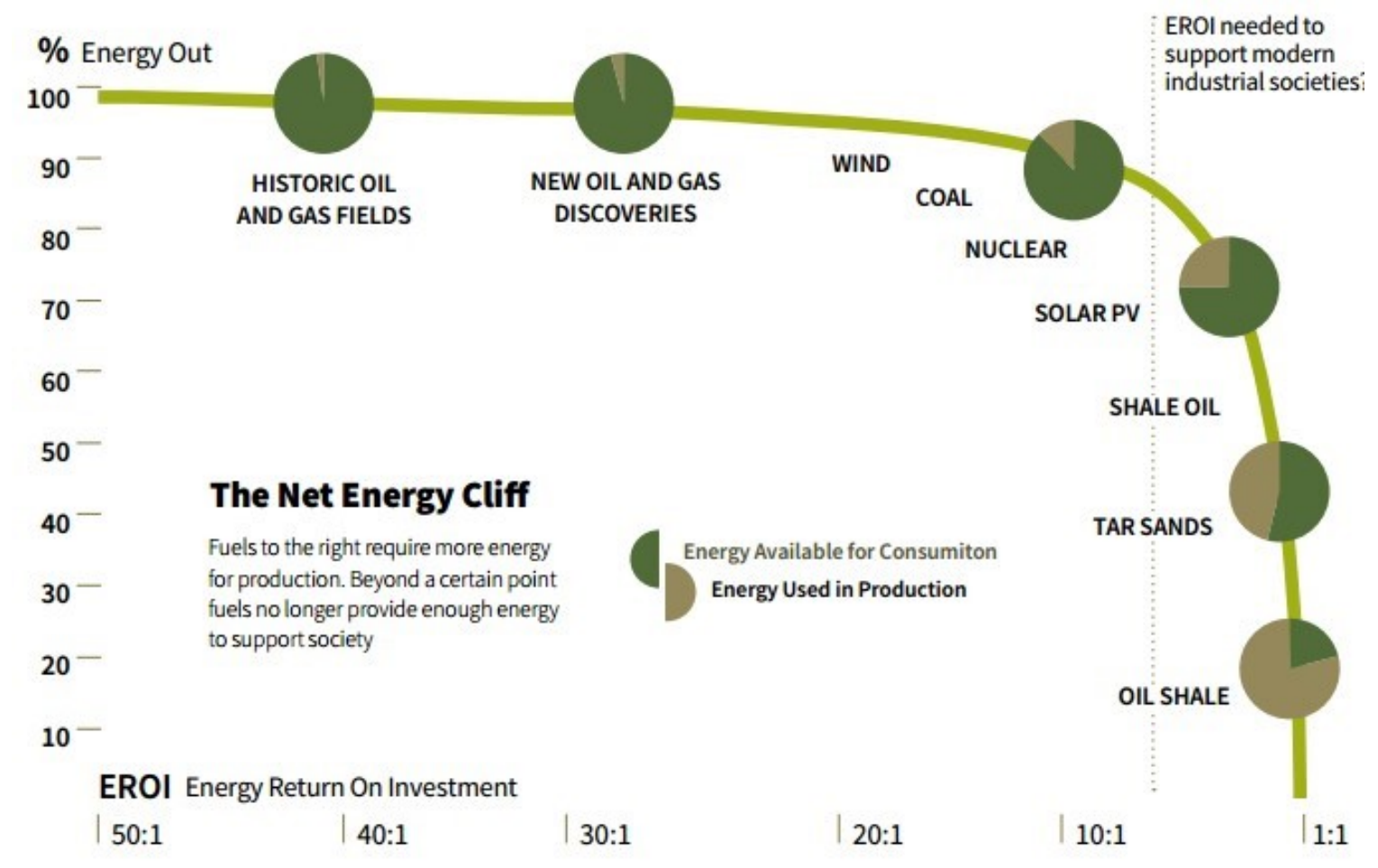

Figure 2.2 The Net Energy Cliff

\section{EROI for financial investments}

The energy intensity ratio is a ratio useful for conversion between energy cost and financial costs (King, Maxwell, \& Donovan, 2015). It is a ratio providing the energy required to produce $\$ 1$ of GDP. This ratio is utilized in the petroleum industry as a correlation with effort to help determine the cost of producing energy in terms of dollar and energy inputs. It is commonly used in the measures of rig deployment, cost of accessing reserves in certain locations, or total deployed force in support of an operation (Moerschbaeher \& Day Jr., 2011). The energy intensity ratio is a dynamic function that is defined (and redefined) based on several factors; including: inflation, efficiencies realized in the process, market factors, and material availability are some factors that may impact the energy intensity ratio. Several sources have promoted the use of energy intensity 
ratios as a proxy to determine EROI of a process where direct energy investment information is not readily available (King C. W., 2010). Thus, our use of such a number will help round-out the energy intensity of portions of the system that cannot be readily determined from an energy perspective but where market pricing may help us draw educated conclusions; such as the energy associated with producing particular feedstocks. 


\section{CHAPTER III}

\section{ANALYTICAL APPROACH}

The focus of this research is to evaluate the EROI of non-traditional energy generation systems, specifically (1) a syngas upgrading energy generation system and (2) a pyrolysis and esterification upgrading energy generation system. The basis of the systems used for this analysis are drawn from systems reported in the literature or made available by the labs developing these systems to for the purpose of determining the viability of these systems as alternative fuel sources in relation to existing conventional, unconventional, and other non-traditional fuel sources. This research will be viewed in light of US national and global energy demands and recent environmental legislation enacted to curb greenhouse gas emissions. This research will provide a framework for drawing boundaries around proposed systems and establishing a methodology for evaluating non-traditional energy generation systems.

An underlying requirement for this analysis is the understanding of how to define the boundary of the non-traditional energy solution as a way to best characterize the EROI and, as a subsequent analysis, the energy return on financial investment (EROFI) of the energy system (Moerschbaeher \& Day Jr., 2011).

As the primary analysis this research will analyze the net energy generation value of the energy generation systems on an annual basis over the lifetime of the systems. We will discount back the net energy flows to determine the EROI of the energy generation 
projects to help determine the viability of these systems. As a part of this analysis, we can also compare the viability of each input stream as of the current technology efficiencies.

As a thought on future research opportunities, this methodology could be used to evaluate unique economic situations; such as subsidies, unique market considerations, changes in input prices or geo-political and socio-economic circumstances (or events).

\section{Boundary design}

To perform this analysis, it will be necessary to clearly define the energy generation system to be analyzed. This includes defining the boundaries for the specific system. From the initial outlay of this analysis, we can envision three separate potential feedstock sources: Crops/Biomass, Municipal Waste, and Sludge. These initial feedstocks may be constrained based on availability of information and whether the identified feedstock can be utilized with in the energy generation system. Outline of energy costs associated with non-conventional energy generation systems provides an outline of idealized delivered feedstocks through a preparation and conversion process to an energy project. By envisioning these separate stocks of input feedstock, we can show the need to accommodate the costs of inputs as a consideration of our boundary design for our analysis. As an example, a ton of green biomass in the form of pine residuals may cost $\$ 18$ while the use of municipal solid waste (MSW) as a feedstock may generate $\$ 9-20$ in income per ton in tipping fees (depending on location). ${ }^{7}$ Once acquired; however, the input feedstock will need to be processed (drying, sorting, cleaning, etc...) before processing can occur. Therefore, we draw our boundaries of our energy generation

\footnotetext{
${ }^{7}$ An impact on the cost of biomass versus MSW is included in the document to demonstrate how the economics of waste recovery can impact a decision to implement a non-traditional energy system.
} 
system upon acquisition of feedstock to account for the "cost" of the feedstock before accounting for the energy spent to process the feedstock.

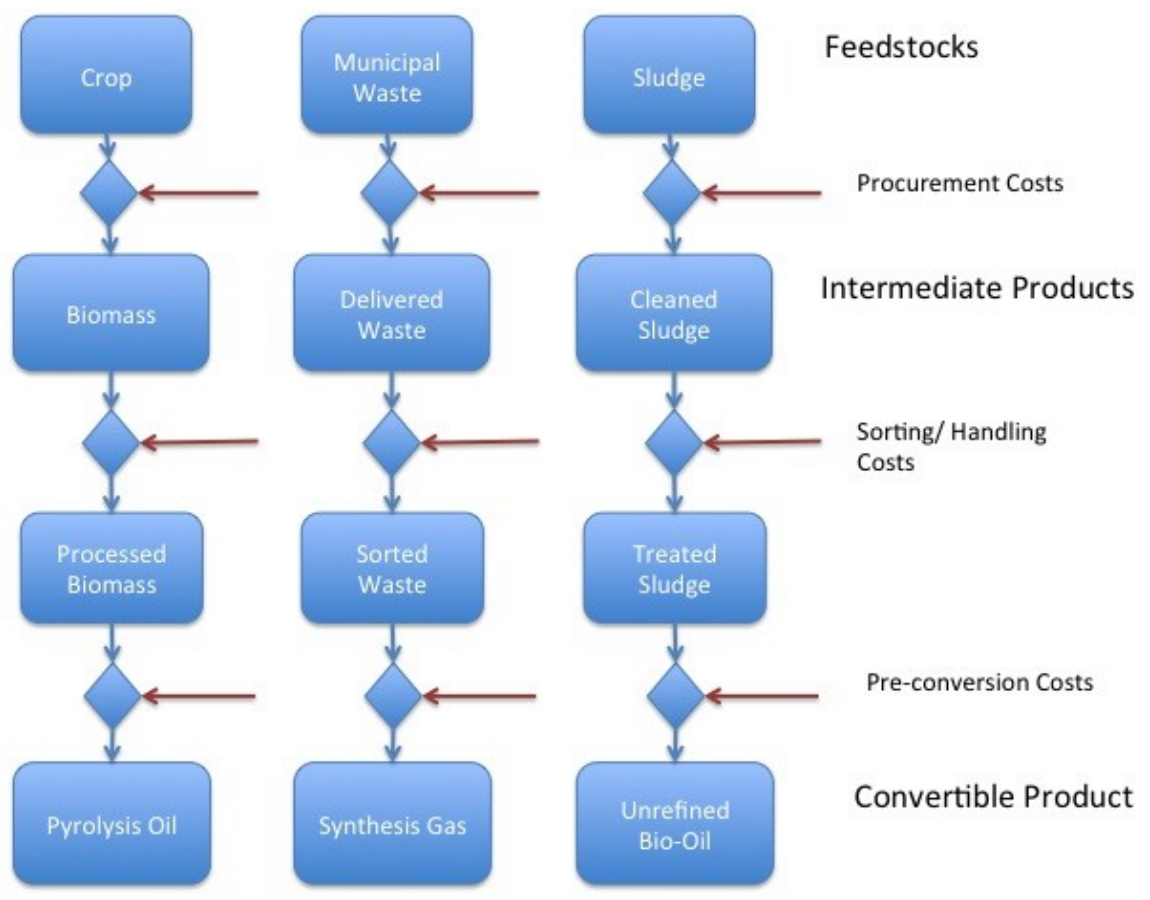

Figure 3.1 Outline of energy costs associated with non-conventional energy generation systems

Based on this outline, we can see the complexity that would be necessary to evaluate each energy system independently and then compare and contrast their viability. However; as we have mentioned, utilizing a mechanism to define the energy system and then evaluate energy flows into and out of that system we can more readily relate, evaluate, and compare energy generation systems that may seem disparate between their 
technological frameworks. To support this methodology, we propose the energy generation system framework below (The energy generation ecosystem).

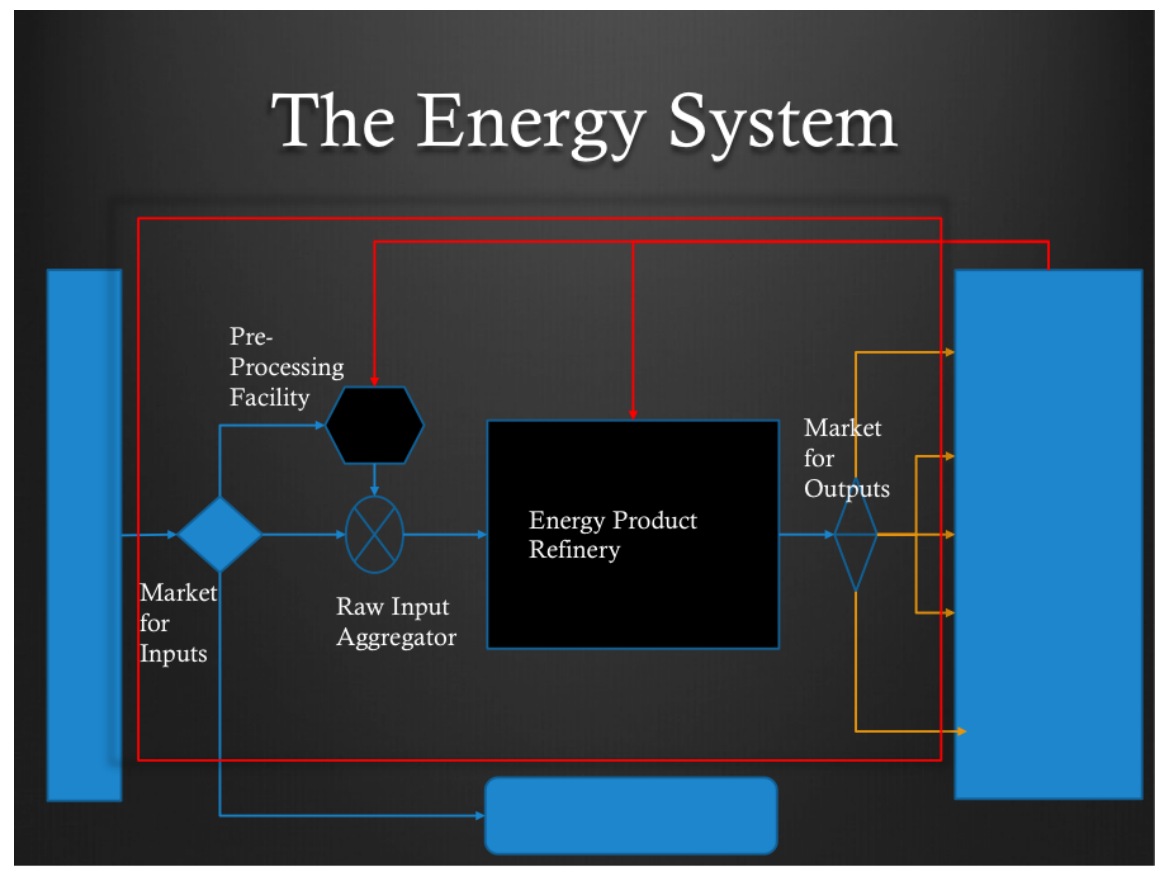

Figure 3.2 The energy generation ecosystem

Using this system as a model, we can develop a methodology for identifying energy moving into and out of the system (The energy generation system). 


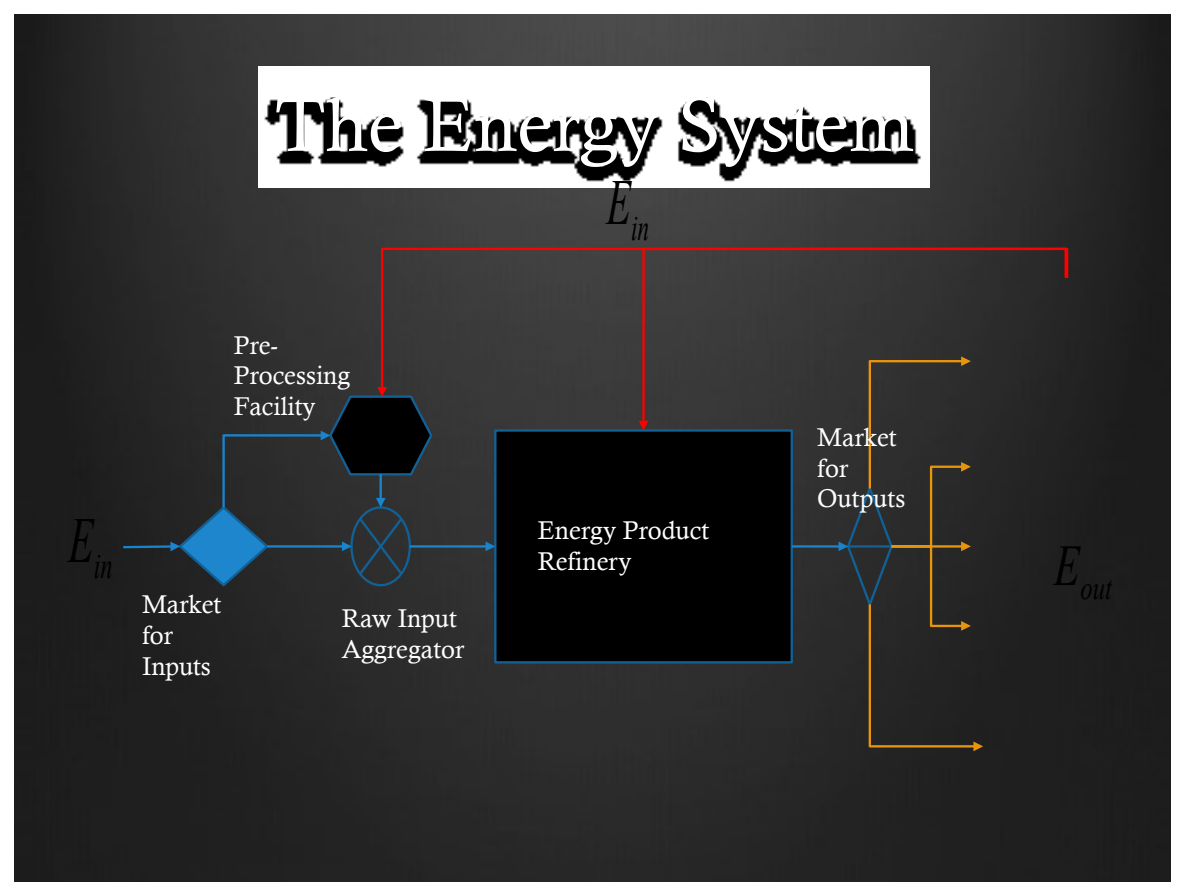

Figure 3.3 The energy generation system

We will also need to develop an energy product(s) and establish the sizing of the proposed energy system. Using this information, we can establish the energy production value of the energy system and begin determining 1) the cost of the energy generation system and 2) the net energy production of the system over its lifetime. This analysis will require the definition of the energy generation facility with an understanding of capacity and approximations of capital and operating expenditures associated with the facility.

Leveraging a modern energy intensity ratio, we will be able to analyze these costs in terms of energy to gain an appreciation for an anticipated EROI associated with the particular energy generation process. To support our analysis, we can utilize an energy intensity factor to help determine the energy cost associated with each feedstock required for energy generation 


\section{Hypothesis}

This research seeks to validate the value of non-traditional energy sources through an evaluation of their net energy value utilizing the EROI mechanism currently being investigated. It is the expectation that through exploitation of non-traditional energy resources we can find alternative energy sources to oil with sufficient EROI (greater than 3 and possibly approaching 8 ) to justify both 1) additional research and development for a result of a lower EROI or 2) immediate investigation as an alternative energy source. This research also seeks to show immediate sources of investigation to help increase the EROI of the defined energy system through a sensitivity analysis of the energy flows around the system.

To achieve this goal, we will define our specific energy generation system, evaluate the capital costs of the non-traditional energy generation system in terms of energy intensity. We will analyze the operational and feedstock costs associated with non-traditional energy systems in terms of energy intensiveness. Finally, we will review the results of the EROI analysis to determine if the technology, at its current state of development, provides for a viable alternative to conventional and un-conventional energy sources. This final analysis can be tuned in the future to account for unique subsidies and sensitivities to different feedstock to help determine the most desirable implementation case given the current state of development.

\section{EROI and its algebra}

EROI has become a unique measure of value on investment in the energy sector. This measure has been explored very recently as a way to examine the value of energy obtained from investments in conventional and unconventional crude oil sources (Hall, 
Lambert, \& Balough, 2014) (Dale, Krumdieck, \& Bodger, 2011) (Heun \& de Wit, 2012). A knowledge base has been developed to determine the EROI for energy products derived from conventional and alternative forms of crude and other energy generation mechanisms, such as nuclear and wind (Brandt, Englander, \& Bharadwj, 2013). However, very little practical information has been utilized to determine the EROI for non-traditional energy sources; such as Fischer-Tropsch, gasification to electricity, gasification to liquid fuel, and pyrolysis.

EROI, as first explored, is a mechanism to provide a "top down" analysis to measure the ratio of energy invested in a system to the energy obtained from the system, see Equation 3.1 (Murphy, 2011). The EROI analysis can also be examined through a related equation to determine a system level approach to energy returns. This system wide approach concerns itself with net energy flows as shown in Equation 3.2.

$$
\begin{gathered}
\text { EROI }=\text { Eout } / \text { Ein } \\
\text { Net Energy }=\text { Eout }- \text { Ein }
\end{gathered}
$$

Net Energy can also be described in terms of the energy entering and leaving the system. This methodology is often applied to the global economy whereby global energy production is divided by the gross global consumption as a way to understand the cost in relative energy terms of production. At a more local level, the energy production system can be described as total energy leaving the production system (Energy for Markets) less the energy needed to run the production system (System Energy) (Dale, Krumdieck, \& Bodger, 2011). To provide some clarity, this term (and its components) can be better described visually, see The energy generation system's energy flows. This is a pictorial 
representation of Equation 3.3 that demonstrates a methodology for tracking energy into and out of the system.

$$
\text { Net Enery Yield }=P-\left(S_{1}+S_{2}\right)
$$

Here, $\mathbf{P}$ is the energy product generated by the energy system. $\mathbf{P}$ is sold to the markets for use as energy or, possibly, for use as a feedstock into other products. $\mathbf{S}_{\mathbf{1}}$ represents energy produced within the system and utilized by the system while $\mathbf{S}_{\mathbf{2}}$ represents energy acquired from the markets to help run the system.

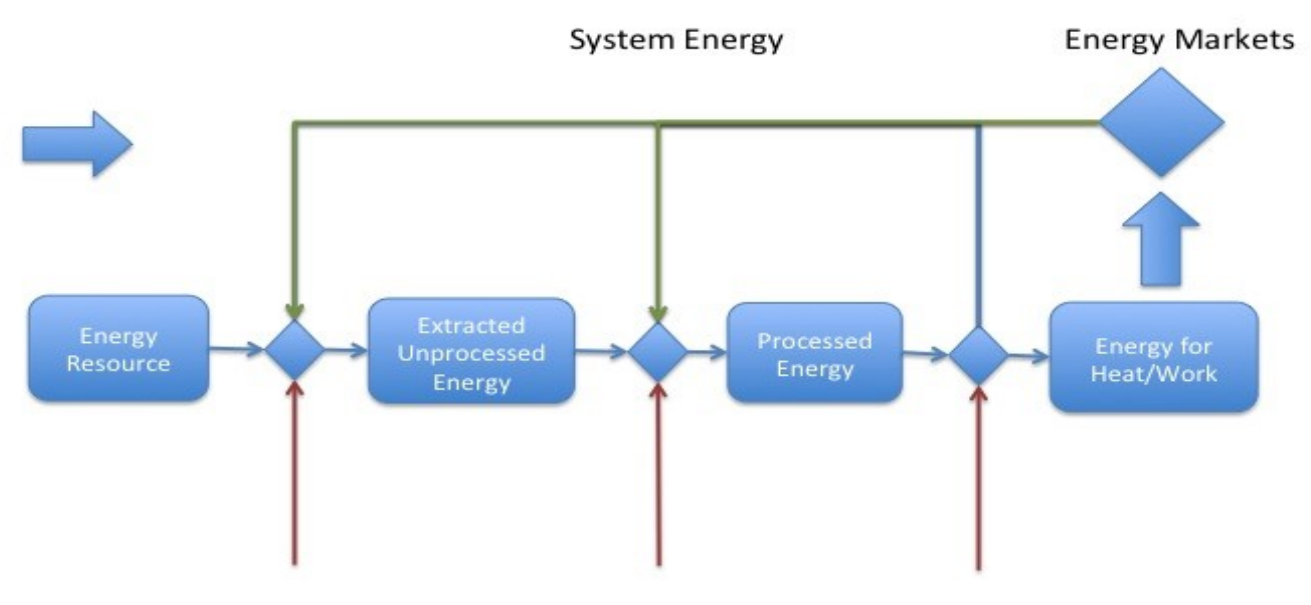

Extraction Loss Processing Loss Distribution Loss

Figure 3.4 The energy generation system's energy flows

Utilizing this equation we have a framework for determining the EROI of an energy system see Equation 3.4 (Dale, Krumdieck, \& Bodger, 2011). By combining these equations we can evaluate the Net Energy of an energy production system (Murphy, 
2011). This methodology is also utilized to determine energy generation and consumption on a macro-scale. ${ }^{8}$

$$
E R O I=\frac{P}{\left(S_{1}+S_{2}\right)}
$$

In the literature several researchers have speculated of a threshold for energy return on investment is necessary to maintain the viability of the modern economy's energy dependence (Murphy, 2011). By utilizing this threshold as a minimum, we can begin a theoretical framework baseline for determining whether a proposed energy system is viable. The unique nature of this construct provides an agnostic approach to the current state of development; as any given system is analyzed the energy costs associated with that system (including technological gains or logistical constraints) could be evaluated to determine the EROI of the specific energy system opportunity.

As a means for understanding the energy required by a nontraditional energy production system we can utilize a Net Energy Returns (NER) methodology to find the energy cost for converting nontraditional sources of energy into an energy product, see

\section{Equation 3.5.}

$$
\text { Net Energy }=\text { Eout } *\left[\frac{(E R O I-1)}{E R O I}\right]
$$

For this analysis (as with Brandt's analysis) our primary concern is the amount of energy invested in the system and the amount of energy returned from its product. We can reduce the variables in Equation 3.6; simplifying our constraints to Brandt's NEER $\mathrm{mm}_{\mathrm{m}}$

\footnotetext{
8 These two equations were utilized to develop the "Net Energy Cliff", a tool used to show the cost of producing energy or energy products. Utilizing the Net Energy Cliff, we can show show that any energy product created through a process below a particular EROI will have a diminishing return on gross energy flowing through the system or into the product. However, for any EROI less than $8($ EROI $<8)$; there is a significant drop in gross energy flowing through the system. At these levels of energy return there is no Net Energy equivalent, instead there is a near negligible difference in the amount of energy returned as a result of the near asymptotic nature of the EROI Threshold. With this knowledge, we can have a clear demarcation for evaluating energy systems relative to their returned energy production; ie a viable alternative to conventional crude oil sources.
} 
equation, Equation 3.7. In this relationship, Brandt has reduced the flows of energy, or costs, of the energy system purely to parasitic consumption (Energyparasitic) and energy provided from the markets $($ Energym $)$.

$$
\begin{gathered}
N E R_{m m}=\frac{\text { Energy }_{\text {out }}}{\sum \text { Energy }_{\text {in }}} \\
N E E R_{m m}=\frac{\text { Energy }_{\text {out }}}{\text { Energy }_{\text {in }}+E_{\text {Energy }} \text { paraitic }}
\end{gathered}
$$

To adjust these equations to suit our purposes, we will need to account for the unique aspects of energy costs related to nontraditional energy products. This will require the identification of boundaries for our energy generation system. These costs will be particular to our feedstock of choice; be it drying costs of green biomass, sorting costs of municipal solid wastes, costs associated with sourcing material across distances, or feed costs associated with sludge treatment. To account for these costs we amend the previous equation. See Equation 3.8.

$$
N E E R_{m m}=\frac{\text { Energy }_{\text {out }}}{\text { Energy }_{\text {in }}+\left(\text { Energy }_{\text {parasitic }}+\sum Z\right)}
$$

In our amended equation $(\Sigma z)$ will be used as a placeholder for the summation of specific unique costs associated with feedstock preparation. Preparation may include handling, processing, harvesting, storing, drying, pre-processing, transportation, or any of a number of other efforts required to prepare nontraditional energy sources for conversion into energy products, See The energy generation system's energy flows.

Utilizing the amended $\mathrm{NEER}_{\mathrm{mm}}$ equation, presented above as Equation 8 and the information provided by the Net Energy Cliff Threshold (Murphy, 2011) we can begin structuring criteria to evaluate the return on a non-traditional energy source. Utilizing 8 as a minimally viable EROI, we can manipulate our $\mathrm{NEER}_{\mathrm{mm}}$ equation to best approximate 
the relationships necessary to achieve a minimally viable EROI from these nontraditional sources of energy products, see Equation 3.9.

$$
8 \times\left(\text { Energy }_{\text {in }}+\left(\text { Energy }_{\text {parasitic }}+z\right)\right)=\text { Energy }_{\text {out }}
$$

Further, as a means to manage adoption and promotion of technology, we can amend our $\mathrm{NEER}_{\mathrm{mm}}$ equation once again to account for discounts or incentives provided to promote the adoption of the technology.

This delta term will allow for a sensitivity analysis for a number of government structured incentive programs that are intended to encourage adoption and promotion of non-traditional energy product conversion technologies.

\section{Net Present Value of Energy Flows}

As a part of our analysis of these systems, it is necessary to amend the view of EROI not to account for a net annual analysis of energy flows but, instead, to account for project lifetime energy flows. The uniqueness in this approach allows for accommodation of capital investment in energy projects while also permitting for fluctuations in costs in flows of stocks of inputs and outputs of the system. It also allows some inclusion of capital reinvestment into the energy generation system over its lifetime. To achieve this analysis we look at energy flows in terms of engineering economics (or project finance) terms. A capital investment in a project is evaluated as a present value (PV) with a magnitude of its total size. While the flows of energy, into and out of the system, will be modeled as a stream of annual flows (annuities) discounted back to the current or present value at the time of the analysis, see Equation 3.10.

$$
P V=\frac{R_{t}}{(1+i)^{t}}
$$


By evaluating the net flows surrounding the system over the course of its projected lifetime, see Equation 3.11, we can establish a framework for comparing the investments between unique non-traditional energy generation systems from a decisionmaking framework.

$$
\mathrm{N} P V(i, N)=\sum_{t=0}^{N} \frac{R_{t}}{(1+i)^{t}}
$$

There will be some conditions that may need to be addressed as a material of equitably comparing unique energy systems to each other. As a practical consideration, this analysis is limited to the energy value invested in a system and an analysis of the energy value directly leaving the system. As the literature has pointed out, it is often difficult to value the energy utilized in the system to create a co-product. It can be even more difficult to evaluate the energy value of the co-products in many situations. To overcome this frustration, we will treat the co-products as waste during an EROI analysis. As an alternative approach to understanding the value of co-products, we can compare the market price of the co-products with the cost of energy in the form of energy products the system utilizes to produce the products. Utilizing this equivalency will help determine the value of co-products through an offsetting mechanism as far as costs go. 


\begin{tabular}{|c|c|c|}
\hline If... & It means... & Then... \\
\hline$N P V<0$ & The energy system & Do not go forward \\
\hline$N P V=,<3$ & $\begin{array}{l}\text { The energy system is about a net zero gain on } \\
\text { energy }\end{array}$ & Do not go forward \\
\hline & & $\begin{array}{l}\text { Evaluate factors to determine if alternative } \\
\text { situations should be considered to make this more }\end{array}$ \\
\hline$N P V=3$ & $\begin{array}{l}\text { The eneryg system could be a sustainable } \\
\text { system }\end{array}$ & $\begin{array}{l}\text { attractive. Consider moving forward if no } \\
\text { alternative systems are avialble }\end{array}$ \\
\hline & $\begin{array}{l}\text { The energy system provides a sustainable } \\
\text { energy net energy return and is a viable }\end{array}$ & $\begin{array}{l}\text { Consider alternatives and evaluate factors in the } \\
\text { analysis to insure some nuanced change in subsidy }\end{array}$ \\
\hline$N P V>3,<8$ & energy investment & or pricing would not negatively impact the model \\
\hline$N P V=,>8$ & $\begin{array}{l}\text { The energy system falls at the optimal point in } \\
\text { the Energy Cliff }\end{array}$ & $\begin{array}{l}\text { Reconsider factor for analysis for senstivity but plan } \\
\text { to move forward }\end{array}$ \\
\hline
\end{tabular}

Figure 3.5 Decision matrix based on EROI analysis result

As a framework for analysis is developed we can explore a go or no-go decision matrix based upon our understanding of the energy generation system opportunity considering the EROI recommendations proposed within the literature, see Decision matrix based on EROI analysis result. 


\section{CHAPTER IV}

\section{ANALYSIS}

Energy derived from natural products and byproducts, such as cellulosic material and waste, is known as bioenergy (Eksioglu, Acharya, Leightley, \& Aora, 2009). The projected increase in renewable fuel generation from sources such as bioenergy is expected to rise from 7.5 BGY in 2012 to $36 \mathrm{BGY}$ by 2022 (Gardner, 2008). Future increases in these sectors will coincide with designated energy demand goals that have been promoted by several country and region authorities; including the United States and the European Union. These goals are in a response to an ever-growing concern related to the economic and fiscal instability associated with dependence on traditional oil sources for fuel, heat, and energy demands.

To support further technology development and to promote the growth of a renewable biofuels industry that will satisfy the stated expectations of production of renewable fuel from the United States government, there has been investment in several energy generation technologies (Gardner, 2008). The investment in these technology areas has come mostly from public money and with some matching private investment. The availability of public money is a necessary component to properly support the stated goals of the federal government. The attribution of private investment money in the research and development pipeline justifies the viability of alternative or renewable energy production technologies in the market system. 


\begin{abstract}
Analysis context
The questions surrounding this scenario could be the subject of several ongoing analyses, but this paper will assume that in the long run, a basis for technology in this sector would provide underlying technical capabilities that provide a market ready energy project into a perfectly competitive market for these energy products. It is the intention of this discussion to treat the products and markets associated with these products as if they are existing products readily available for the competitive market. We will also assume a mature, competitive market exists for the feed stocks necessary for energy generation (including cellulosic, biomass, and energy) thereby allowing a more straightforward analysis of the proposed energy systems.

With these external considerations in mind we can begin defining our energy generation systems for analysis. For this analysis we will consider two systems to model: i) a fast pyrolysis fluidized bed reactor coupled with a fuel upgrading system and ii) a syngas generation plant coupled with an upgrading system (such as a Fischer-Tropsch system). For our analysis there will be several underlying features associated with these systems that will be constant (Assumptions of our energy generation systems). These features include system sizing and operational time per year primarily to promote a simple, direct comparison to each system. We understand that practical implementation of either system may result in differing sizing constraints that could lead to alternative efficiencies. However; the intent of this analysis is to demonstrate a near apples-to-apples comparison of EROI between these systems, so we can more readily evaluate EROI of the systems.
\end{abstract}


For convenience, we propose a capacity boundary of 100 tons per day processing facility. These systems will operate on a continuous cycle ( 24 hours a day) for 333 days a year (92.5\%). This presents us with 8,000 production hours per year. As these systems are unique and produce different end products, their respective energy products (bio-oil compared to bio diesel) are converted to diesel equivalent energy values (in BTUs) and we rely on reported energy production conversion values available in the literature: (i) 75,500 BTU's per gallon of bio-oil (Stewart, 2004) (ii) 120,000 BTU's per gallon of biodiesel (Gable \& Gable, 2017), and (iii) 25,000,000 BTU's per ton of char (UT Knoxville Biorefinery Site, 2017). For a general standpoint, we adopt an efficiency value of $85 \%$ for both models. This efficiency value allows for independent manipulation of the productivity of any energy system; which helps to account for unexpected downtime, and permits a variable system for productivity values as technology in this space progresses independently of each model

\begin{tabular}{c}
\hline Pyrolysis Production System Sizing \\
\hline \hline 100 tons per day \\
333 days per year \\
24 hours per day \\
8,000 operational hours per year \\
33,333 tons per year \\
4 tons per hour \\
7 pounds per gallon \\
120,000 BTU's per gallon of diesel (diesel equivalent) \\
$25,795,384$ BTU's per ton of char \\
$85 \%$ Efficiency
\end{tabular}

\begin{aligned} \hline \multicolumn{1}{c}{ Syngas Production System Sizing } \\ \hline \hline 100 tons per day \\ 333 days per year \\ 24 hours per day \\ 8,000 operational hours per year \\ 33,333 tons per year \\ 4 tons per hour \\ 10 pounds per gallon \\ 75,500 BTU's per gallon of bio-oil (diesel equivalent) \\ $25,795,384$ BTU's per ton of char \\ $85 \%$ Efficiency \end{aligned}

Figure 4.1 Assumptions of our energy generation systems

A unique attribute of these systems is their ability to be tailored to a variety of input feedstocks. Fast pyrolysis and syngas can be applied to biomass, cellulosic material, 
wood chips, municipal waste, and possibly a number of other raw feedstocks. As a result of the variance in these feedstocks there can be variance in the energy consumed to produce and process energy products from the system. Moisture content, mineral content, and organic material structure of the input materials alone can impact the energy cost of producing and distilling out energy products. These variables can also be accounted for in the efficiency rating that, at the beginning of any analysis will take on the role of a "beta" factor to capture unknowns. Using this apples-to-apples comparison, we can see that current Syngas and Pyrolysis production and upgrading plants produce energy output equivalents that are relatively similar.

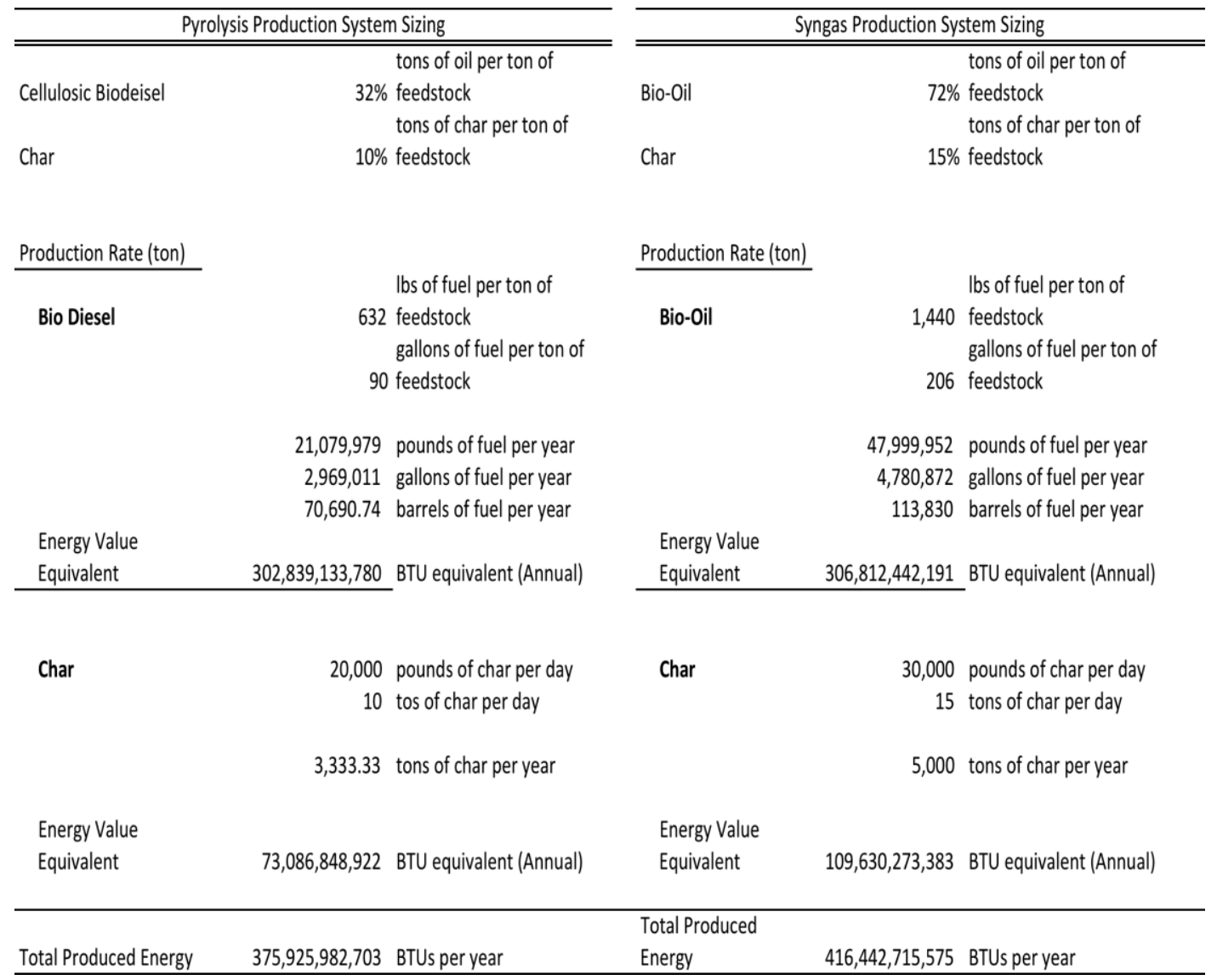

Figure 4.2 Energy generation production capacity 
The fast-pyrolysis system analyzed in Energy generation production capacity is drawn from information produced by Prof. Philip Steele's lab at Mississippi State University's Forest Products Research Lab. The energy generation information is extrapolated from tests performed with an $80 \%$ pine and $20 \%$ miscanthus feedstock (Mithcell \& Steele, 2014). The analysis relies on a 32\% conversion of feedstock to cellulosic biodiesel and a 10\% feedstock conversion rate to char. Not accounted for in this model is the energy value of byproducts resulting from this fast-pyrolysis reactor. These byproducts may show value in the chemical commodity markets and could be incorporated into this model through methodologies described below.

The syngas system analyzed is proposed by an early stage company targeting upgraded syngas from mixed sources to generate hydrocarbons. This syngas system is based on a pyrolysis reactor system proposed to the New Hampshire Governor's Office of Energy and Community Services (Stewart, 2004) for the generation of bio-oil from low-grade woody material (blend of white wood and tree bark). This analysis proposes a range of products based on system attenuation and properties of feedstock. However underlying these ranges is a target production rate of $72 \%$ bio-oil yield and a char yield of $15 \%$. Additional bi-products are also produced from this system and not accounted for in our current model.

Both models are predicated on a thermochemical reactor system to convert biomass to energy products. Thermochemical conversion of cellulosic material occurs when the materials are heated either through a gasification or pyrolysis reaction. These techniques share similar production factors; heat is introduced to the feedstock under low oxygen conditions to generate a product that can be converted or upgraded to biofuels 
and other chemicals. Syngas is composed of a mixture of carbon monoxide and hydrogen. Similarly, the pyrolysis reaction generates a product known as bio-crude or pyrolysis oil that can be used as a fuel immediately or upgraded into other energy products and chemicals. A key difference in the two processes is the temperature where the conversion reaction occurs: syngas is produced in reactors at temperatures in excess of $600^{\circ} \mathrm{C}$ while pyrolysis occurs at temperatures below $500^{\circ} \mathrm{C}$ (Stewart, 2004).

Several companies have proposed these reactor systems and pilot plants have been demonstrated at sizing up to 45 tons per day (Dynamotive). Proposed costs for these reactors range from $\$ 2.6 \mathrm{M}$ ( 25 tons per day) to $\$ 5.6 \mathrm{M}$ for a 100 tons per day system (Stewart, 2004). We assume these costs to be low or to not account for other factors (including the costs of land and infrastructure) so we target a capital expenditure for a proposed system as $\$ 10 \mathrm{M}$ for 100 tons per day, see Operational costs of the energy generation systems. These costs are not directly in line with the proposed system costs from the Steele lab; however, it is within the ballpark of the anticipated reactor costs proposed by their lab (Mithcell \& Steele, 2014). 


\begin{tabular}{|c|c|c|c|c|c|c|c|}
\hline \multicolumn{8}{|c|}{ Operational Costs } \\
\hline \multicolumn{4}{|c|}{ Pyrolysis Production System } & \multicolumn{4}{|c|}{ Syngas Production System } \\
\hline Operational & & & & Operational & & & \\
\hline Process Energy & & & & Process Energy & & & \\
\hline Biodiesel & & $3,884.83$ & BTU's per ton & Electircity Cost & $\$$ & 0.072 & per Kilowatt hour \\
\hline Dryer & & $1,777.00$ & BTU's per ton & Electricity Usage & & $7,750,000$ & $\mathrm{kWh}$ \\
\hline Canibalistic Consumption & & & & Canibalistic Consumption & & & \\
\hline Biodiesel & & $10 \%$ & & Bio-Oil (Canabilzed) & & $6 \%$ & \\
\hline Char & & $20 \%$ & & Char & & $31 \%$ & \\
\hline Feedstock & $\$$ & 40.00 & per ton & Feedstock & $\$$ & 18.00 & per ton \\
\hline Labor & $\$$ & $35,000.00$ & & Labor & $\$$ & $35,000.00$ & \\
\hline Overhead & & $20 \%$ & & Overhead & & $20 \%$ & \\
\hline Staff & & 10.00 & & Staff & & 10.00 & \\
\hline Capital Costs & & & & Capital Costs & & & \\
\hline Plant & $\$ 1$ & $, 000,000.00$ & & Plant & & $000,000.00$ & \\
\hline Maintenace & & $5 \%$ & Plant Costs & Maintenace & & $5 \%$ & of CAPEX \\
\hline Royalty/License & & $3 \%$ & & Royalty/License & & $3 \%$ & \\
\hline Inflation & & $2 \%$ & & Inflation & & $2 \%$ & \\
\hline
\end{tabular}

Figure 4.3 Operational costs of the energy generation systems

Operational costs account for feedstock, energy consumed for running the system (such as drying feedstock and cannibalistic consumption), labor and maintenance. These costs also include anticipated royalty and licensing fees generally considered as costs of doing business for these types of systems.

\section{EROI Analysis}

Analyzing the energy system based on energy product value will enable a method for competitive analysis of the different energy production systems through conventional project valuation methods. This methodology will also allow for evaluating energy systems based on the EROI of any particular implementation scenario. Additionally, the ability to analyze the EROI of any energy system will provide an immediate current 
equivalent market system that provides a basis for this analysis. Without this baseline for analysis, there would be difficulty in directly comparing viability of energy systems available to us.

\section{Converting money to energy}

An essential factor in this analysis will be the use of energy units (BTU's in our case) as the underlying common energy unit. To do this we must convert other values into energy units (and then convert these units to BTU's specifically). Although this might seem like a unique approach this type of analysis is an essential function that money serves. As a medium of exchange and a unit of account, money provides a common currency that allowed civilization to evolve from a barter economy and promoted the adoption of the social contract and our current market systems (Collins, Schuster, \& and Greenham, 2012). Numerous studies have been performed equating the then "current" energy quantity that can be purchased on the open market with a specific currency (Rapier, 2010). Although this approach is simplistic and seems straightforward, it is not the most precise relationship that we can use to translate project costs to an energy equivalent.

Instead we can look to energy efficiency ratios, specifically the mean energy intensity for a specific economy to provide a mechanism to relate project costs to an energy equivalent. The mean energy intensity is used to describe the amount of energy used to produce one unit of economic value (Upadhyaya, 2010) (National Academy of Engineering, National Research Council, 2008). To find the energy intensity we divide the unit of energy produced in an economy by the GDP of that economy (International Energy Agency, 2008). In the US, in 2005, the US energy intensity was calculated to be 
about 8,500 BTU's / \$ - this comes from 99.74 quads of energy consumed divided by a GDP of $\$ 11.75$ Trillion in the US.

To better approximate the mean energy intensity value for a more current value we can use more recently reported data for GDP and energy consumption to better approximate the energy intensity. In 2015, the US Energy Information Administration has published US energy consumption quantities at 97.363 Quads (US Energy Information Administration, 2018). The World Bank reports US GDP of \$18.04 Trillion in 2015. As a result, the increase in productivity coupled with a decline in energy consumption results in an energy intensity ratio of about $5,400 \mathrm{BTUs} / \$ .{ }^{9}$ This analysis is supported by the reported energy intensity ratio reported by The World Bank of 5.6 MJ/\$ (approximately 5,600 BTUs/\$) (The World Bank, 2018). ${ }^{10}$

\section{Addressing Costs}

As we look to model the energy generation system, we need to understand the costs associated with developing and implementing the system. Based on proposed plans and assumptions drawn from local and reported sources, we propose the energy equivalents in terms of 2015 energy intensity ratio in Production costs in terms of energy equivalents.

\footnotetext{
${ }^{9}$ It is interesting to see how efficiency and productivity could have a marked impact on the total energy cost associated with capital expenditures during the construction phase of the energy generation system.

${ }^{10}$ As the US economy tends towards a service economy, we can see energy use trends slightly down while productivity (as measured in GDP) trends up. This dramatically reduces the mean energy intensity of this year that could significantly augment this analysis. A more useful ratio would be would be an energy intensity ratio directed at the mean energy intensity of specific industrial sector in the target economy (ie the mean energy intensity ration of the construction industry in the target country/state).
} 


\begin{tabular}{|c|c|c|c|c|c|}
\hline \multicolumn{6}{|c|}{ Converting Costs to Energy Equivalents } \\
\hline Annual Labor & & & Energy Equiva & (in 2015 equivaler & nts) \\
\hline Labor & $35,000.00$ & & & $226,669,623$ & BTU's \\
\hline Overhead & $20 \%$ & & & & \\
\hline Staff & 10.00 & & & $2,266,696,231$ & BTU's \\
\hline Capital Costs & & & Capital Costs & & \\
\hline Plant & $\$ 10,000,000.00$ & & Plant & $53,968,957,871$ & BTU's \\
\hline Maintenace & $5 \%$ & Plant Costs & Maintenace & $2,698,447,894$ & BTU's \\
\hline Royalty/Licer & $3 \%$ & & Royalty/Licer & $1,619,068,736$ & BTU's \\
\hline Inflation & $3.24 \%$ & & Inflation & $1,748,594,235$ & BTU's \\
\hline
\end{tabular}

Figure 4.4 Production costs in terms of energy equivalents

With this evaluation in place, we have now converted all energy, labor, and capital expenditures flows into energy equivalent flows. Note, a full analysis of this system would account for changes in costs due to changes in energy intensity analysis. However, for our purposes, we are determining the energy return on investment from a pre-planning phase and have accounted for changes in this analysis through the incorporation of efficiency ratings of the systems.

\section{EROI application}

We will focus our approach for this analysis on a traditional investment analysis technique. Net Present Value (NPV) is the present value of cash flows at the required rate of return of your product compared to your initial investment (Gallo, 2014). The intent of NPV analysis is to evaluate the present value of a decision based on the sum of all future cash flows associated with that decision. Alternative strategies for evaluating investment decisions might include an internal rate of return analysis or a payback method. Both of 
these methods would provide valuable insight for evaluating investment decisions; however, the use of NPV specifically allows us to analyze an energy system investment opportunity in light of the EROI analysis we have proposed.

\section{NPV analysis of energy flows}

A key factor for NPV analysis is the determination of the discount rate. Inflation can be an appropriate discount rate to determine the future cost of a product. With this in mind, we can check the Consumer Price Index to get a sense of the inflation associated with the cost in energy. From 2000 to 2018 the reported average inflation of energy was 3.24\% (Bureau of Labor Statistics). This will become a discount rate for the cost of energy used in the future. It will also serve as the discount rate for the energy products generated in the by the system.

Our analysis will take into account the in-flows and out-flows of the energy system within any given calendar/fiscal year. Energy in-flows will include raw energy (from the market and cannibalistic), char, feedstock, labor, maintenance, royalties and fees. These costs will be converted to energy equivalents (in BTU's). Since our analysis is simple we will assume these costs are fixed and dependent upon the size of the energy generation system.

We will also evaluate our energy out-flows in terms of their energy equivalents. As these systems are hypothetically, we are only accounting for the designating energy products and by-products (upgraded syngas, pyrolysis oil, and char). Specialty chemicals are anticipated but not accounted for in this system, as they are not designated. To include these values in future analysis we would convert their market value into BTU's through the energy intensity index and then discount those value back to present dollars. 
The analysis for these flows is provided below in Gasification and Syngas Upgrading EROI Analysis and Pyrolysis and Esterification EROI Analysis. This analysis provides an example of Year 0 capital outlays in terms of energy (BTU's) as well as examples of energy flows, in and out, for Year 1 and Year N. The analysis assumes a 20year energy generation system lifetime. By summing up the net energy flows for each year and discounting those energy flows back to present time (Year 0) we can determine whether the energy investment in either of these systems will be a net energy gain.

As we convert the flows in the energy systems into energy equivalents we can take a ratio of the net energy generation over time divided by the energy investment into the system. This helps us determine where on the EROI cliff these technologies, at this time, stand.

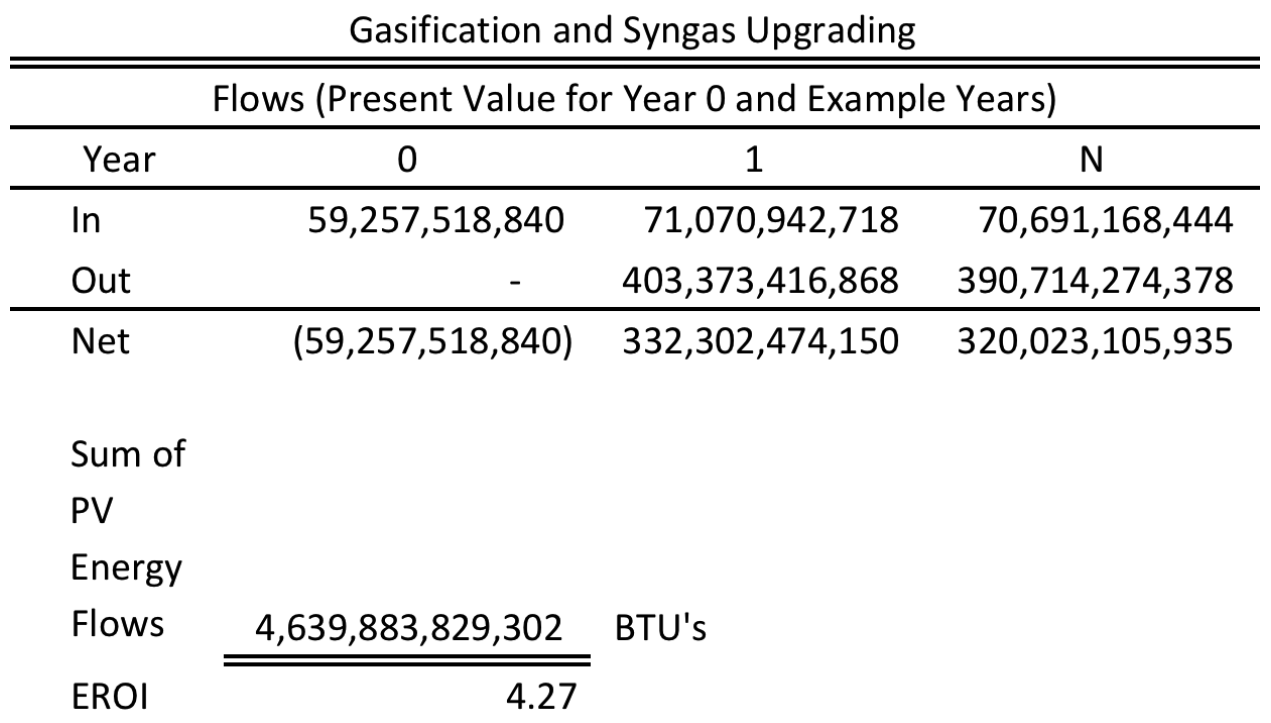

Figure 4.5 Gasification and Syngas Upgrading EROI Analysis 
As we can see from this analysis, the Gasification and Syngas Upgrading system, under our conditions, has an EROI of 4.27 indicating it is a productive energy generation system. Although not ideal under the current techno-economic model currently available, it is approaching the ratio reported earlier, and described in The Net Energy Cliff, that indicates the net energy necessary to support modern industrial society.

Pyrolysis and Esterification

\begin{tabular}{lcrr}
\hline \hline \multicolumn{4}{c}{ Flows (Present Value for Year 0 and Example Years) } \\
\hline Year & 0 & 1 & $\mathrm{~N}$ \\
\hline In & $58,859,435,700$ & $66,687,983,928$ & $64,980,237,023$ \\
Out & - & $364,128,228,112$ & $352,700,724,634$ \\
\hline Net & $(58,859,435,700)$ & $297,440,244,183$ & $287,720,487,611$
\end{tabular}

Sum of PV
Energy Flows
EROI

Figure 4.6 Pyrolysis and Esterification EROI Analysis

Evaluating the Pyrolysis and Esterification system, we report a theoretical EROI of 4.88 under our conditions. This confirms this system is a productive energy generation system.

As we can see from the results the modeled Pyrolysis Reactor System and the Upgraded System Generation System provided for an EROI greater than 4. This means an energy investment in either of these systems will return a $4 \mathrm{X}$ return on energy investment on discounted energy flows. Based on our framework above, Decision matrix 
based on EROI analysis result, both systems would prompt additional investigation as viable energy generation system alternatives.

With additional technology development, decreases in the mean energy intensity index, and depending on market value of energy and byproducts, these technologies are nearing their viability as proposed by the Net Energy Cliff analysis. 


\section{CHAPTER V CONCLUSION}

Reviewing the analytical approach above, we demonstrate here an approach to evaluating energy generation system investments that is not predicated on immediate currency valuations alone. Although the analysis provides for a means to convert real time dollars into an energy value equivalent, the energy equivalent might be less impacted by socio-political machinations. Instead, the energy value is dependent on the immediate economic productivity of the society that can be evaluated on a sector-bysector basis or could be evaluated over a period of time to "smooth" out the impacts of socio-political issues in the specific region. Using this analysis and applying it to what we know about existing energy generation systems we can see that non-traditional systems are on the cusp of long-term viability, as the technologies currently exist.

We can also show the sensitivity of certain input factors on the system. For instance, converting the input feedstock on in the Syngas Generation System to MSW and assuming a "tipping fee" of $-\$ 10$ per ton results in a slightly higher EROI. 


\section{REFERENCES}

ARPA-E. (2016, February 2016). ARPA-E Projects. (A.-E. P. Affairs, Producer, \& United States Department of Energy) Retrieved December 15, 2017, from ARPAE: https://arpa-e.energy.gov/?q=news-item/arpa-e-projects-receive-more-125billion-private-follow-funding-transformational-energy

ARPA-E. (2009, August 9). Authorization of ARPA-E. (A.-E. P. Affairs, Producer, \& US Department of Energy) Retrieved December 15, 2017, from ARPA-E: https://arpa-e.energy.gov/arpa-e-site-page/authorization

Baumeister, C., \& Kilian, L. (2013). Do Oil Price Increases Cause Higher Food Prices? Economic Policy, 29 (80), 691-747.

Brandt, A. R., Englander, J., \& Bharadwj, S. (2013). The energy efficiency of oil sands extraction: Energy return ratios from 1970-2010. Energy, 55, 693-702.

Bureau of Labor Statistics. (n.d.). Consumer Price Index. Washington, DC, USA: available at: http://www.in2013dollars.com/Energy/price-inflation.

Carbajales-Dale, M., Barnhard, C. J., Bradnt, A. R., \& Benson, S. M. (2014). A better currency for investing in a sustainable future. Nature Climate Change, 4, 524527.

Collins, J. R., Schuster, L., \& and Greenham, T. (2012). Energising Money: An Introduction to Energy Currencies and Accounting. New Economics Foundation. The 40 Foundation.

Dale, M., Krumdieck, S., \& Bodger, P. (2011, February 1). A Dynamic Function for Energy Return on Investment. Sustainability .

Donohoo-Vallett, P. (2016). Accounting Methodology for Source Energy of NonCombustible Renewable Electricity Generation. U.S. Department of Energy, Energy Efficiency \& Renewable Energy. Washington D.C.: US. DOE.

Eksioglu, S. D., Acharya, A., Leightley, L. E., \& Aora, S. (2009). Analyzing the design and management of biomass-to-biorefinery supply chain. Computers \& Industrial Engineering , 57, 1342-1352.

Gable, C., \& Gable, S. (2017, August 31). Gasoline Gallon Equivalents. ThoughtCo. 
Gallo, A. (2014, November 19). A Refresher on Net Present Value. (A. Igantius, Ed.) Harvard Business Review .

Gardner, D. (2008). Biomass Overview for Advisory Council on Energy. National Renewable Energy Laboratory, Renewable Fuels \& Vehicle Systems. NREL.

Hall, C. A., Lambert, J. G., \& Balough, S. B. (2014). EROI of different fuels and implications for society. Energy Policy, 64, 141-152.

Heun, M. K., \& de Wit, M. (2012). Energy return on (energy) invested (EROI), oil prices, and energy transitions. Energy Policy, 40, 147-158.

International Energy Agency. (2008). Worldwide Trends in Energy Use and Efficiency: Key Insights from IEA Indicator Analysis. International Energy Agency, Head of Communication and Information Office. Paris: IEA Publications.

King, C. W. (2010). Energy intensity ratios as net energy measures of United States energy production and expenditures. Environmental Research Letters , 5 (4), 044006 .

King, C. W., Maxwell, J. P., \& Donovan, A. (2015). Comparing World Economic and Net Energy Metrics. Energies , 8, 12949-12974.

Majcher, K. (2015, July 15). Is ARPA-E Making Any Progress. MIT Technology Review: Sustainable Energy . Boston, Massachusetts, USA: MIT Technology Review.

Marchand, R. A. (2017, November 28). Congress Should Slash Energy Department's Advanced Research Program. Economics21 . (D. Furchtgott-Roth, Ed.) New York City, New York, USA.

Mervis, J. (2017, April 28). DOE freezes millions in high-tech energy grants and gags staff. Science. Science. Retrieved from Science: http://www.sciencemag.org/news/2017/04/doe-freezes-millions-high-tech-energygrants-and-gags-staff

Mithcell, B., \& Steele, P. (2014). MSU Biodiesel Economic Model. Economic Model, Mississippi State University, Department of Forest Products, Starkville.

Moerschbaeher, M., \& Day Jr., J. W. (2011). Ultra-Deepwater Gulf of Mexico Oil and Gas: Energy Return on Financial Investment and a Preliminary Assesment of Energy Return on Energy Investment. Sustainability, 3 (10), 2009-2026.

Murphy, D. (2011, November 25). The Energy Return on Investment Threshold. Retrieved December 15, 2017, from The Oil Drum: Discussions about Energy and our Future: http://www.theoildrum.com/node/8625 
National Academies. (2007). Rising Above the Gathering Storm: Energizing and Employing America for a Brighter Economic Future. The National Academies of Science, Engineering, and Medicine, NAS Council. Washington DC: The National Academies Press.

National Academy of Engineering, National Research Council. (2008). Energy Intensity and Energy Efficiency. In Energy Futures and Urban Air Pollution: Challenges for China and the United States (DOI: 10.17226/12001 ed., pp. 161-182). Washington, DC: The National Academic Press.

Nigatu, G., Hjort, K., Hansen, J., \& Somwaru, A. (2014). The Impacts of Energy Prices on Global Agricultural Commodity Supply. Agriculture and Applied Economics Association 2014 Proceedings. Minneapolis: AAEA.

OECD. (2008). Rising Food Prices: Causes and Consequences. Organization for Economic Co-operation and Development, Agricultural Trade. Paris: OECD.

Petroff, A., \& Yellin, T. (2015, 11 3). What it Costs to Produce Oil. (CNN) Retrieved 12 15, 2017, from CNNMoney.com: http://money.cnn.com/interactive/economy/thecost-to-produce-a-barrel-of-oil/index.html?iid=EL

Rapier, R. (2010, January 26). The Price of Energy. (R. Lane, Ed.) Forbes .

Smith, J. L., \& Lee, T. K. (2017). The Price Elasticity of U.S. Shale Oil Reserves. U.S. Energy Information Association, Independent Statistics and Analysis. Washington D.C.: U.S. EIA.

Stewart, G. W. (2004). Bio-Oil Commercialization Plan. Cole Hill Associates, Blufton, SC.

Supermajordammerung. (2013, August 3). The day of the huge integrated oil company is drawing to a close. The Economist .

The World Bank. (2018). Energy Intensity Level of Primary Energy. (T. W. Bank, Producer, \& The World Bank) Retrieved 03 20, 2018, from WorldBank.Org: https://data.worldbank.org/indicator/EG.EGY.PRIM.PP.KD?end=2014\&start=20 09\&year_low_desc $=$ true

Thomas, V., Choi, D., \& Luo, D. (2015). Biofuel Lifecycle Energy and Environmental Impacts The Challenges of Co-product Allocation. In S. Eksioglu, S. Rebennack, \& P. Pardalos (Eds.), Handbook of Bioenergy, Energy Systems. Springer.

Timmons, D., Harris, J. M., \& Roach, B. (2014). The Economics of Renewable Energy. Tufts University, Global Development And Environment Institute, Medford. 
Upadhyaya, S. (2010). Compilation of Energy Statistics for Economic Analysis. United Nations Industrial Development Organization, Development Policy and Strategic Research Branch. Vienna: UNIDO.

US Energy Information Administration. (2018). eia Beta. (U. E. Administration, Producer) Retrieved 03 20, 2018, from https://www.eia.gov/beta/international/data/browser/\#/?pa $=000000001 \mathrm{~s} \& \mathrm{c}=0000$ $0000000000000000000000000000000000000000002 \& \mathrm{ct}=0 \& v s=I N T L .44-2-$ USA-QBTU.A\&vo=0 \&pin $=\mathrm{a} \& \mathrm{v}=\mathrm{H} \& \mathrm{end}=2015 \& \mathrm{~s}=\mathrm{INTL} .44-2-\mathrm{NOAM}-\mathrm{QBTU} . \mathrm{A}$

US Energy Information Administration. (2017, September). Oil: Crude and Petroleum Products Explained. (US EIA) Retrieved December 15, 2017, from EIA: https://www.eia.gov/energyexplained/index.cfm?page=oil_refining

UT Knoxville Biorefinery Site. (2017). Pyrolysis Char Heating Values. UT Knoxville, Chemical and Biomolecular Engineering, Knoxville.

Williams, J. (2011). Oil Price History and Analysis. London, AR, USA: WTRG Economics. 